\title{
Selective CO Methanation on Highly Active Ru/TiO2 Catalysts: Identifying the Physical Origin of the Observed Activation/Deactivation and Loss in Selectivity
}

\author{
Abdel-Mageed, Ali M.; Widmann, Daniel; Olesen, Sine Ellemann; Chorkendorff, Ib; Behm, R. Jürgen
}

Published in:

A C S Catalysis

Link to article, DOI:

10.1021/acscatal.8b00384

Publication date:

2018

Document Version

Peer reviewed version

Link back to DTU Orbit

Citation (APA):

Abdel-Mageed, A. M., Widmann, D., Olesen, S. E., Chorkendorff, I., \& Behm, R. J. (2018). Selective CO Methanation on Highly Active $\mathrm{Ru} / \mathrm{TiO}_{2}$ Catalysts: Identifying the Physical Origin of the Observed Activation/Deactivation and Loss in Selectivity. A C S Catalysis, 8, 5399-5414.

https://doi.org/10.1021/acscatal.8b00384

\section{General rights}

Copyright and moral rights for the publications made accessible in the public portal are retained by the authors and/or other copyright owners and it is a condition of accessing publications that users recognise and abide by the legal requirements associated with these rights.

- Users may download and print one copy of any publication from the public portal for the purpose of private study or research.

- You may not further distribute the material or use it for any profit-making activity or commercial gain

- You may freely distribute the URL identifying the publication in the public portal 


\section{Article}

Subscriber access provided by DTU Library

\section{Selective $\mathrm{CO}$ methanation on highly active $\mathrm{Ru} / \mathrm{TiO}$ catalysts: Identifying the} physical origin of the observed activation / deactivation and loss in selectivity

Ali M. Abdel-Mageed, Daniel Widmann, Sine E. Olesen, lb Chorkendorff, and R. Jürgen Behm

ACS Catal., Just Accepted Manuscript • DOI: 10.1021/acscatal.8b00384 • Publication Date (Web): 27 Apr 2018

Downloaded from http://pubs.acs.org on April 29, 2018

\section{Just Accepted}

"Just Accepted" manuscripts have been peer-reviewed and accepted for publication. They are posted online prior to technical editing, formatting for publication and author proofing. The American Chemical Society provides "Just Accepted" as a service to the research community to expedite the dissemination of scientific material as soon as possible after acceptance. "Just Accepted" manuscripts appear in full in PDF format accompanied by an HTML abstract. "Just Accepted" manuscripts have been fully peer reviewed, but should not be considered the official version of record. They are citable by the Digital Object Identifier (DOI®). "Just Accepted" is an optional service offered to authors. Therefore, the "Just Accepted" Web site may not include all articles that will be published in the journal. After a manuscript is technically edited and formatted, it will be removed from the "Just Accepted" Web site and published as an ASAP article. Note that technical editing may introduce minor changes to the manuscript text and/or graphics which could affect content, and all legal disclaimers and ethical guidelines that apply to the journal pertain. ACS cannot be held responsible for errors or consequences arising from the use of information contained in these "Just Accepted" manuscripts. 


\title{
Selective CO Methanation on Highly Active $\mathrm{Ru} / \mathrm{TiO}_{2}$ Catalysts: Identifying the Physical Origin of the Observed Activation / Deactivation and Loss in Selectivity
}

\author{
Ali M. Abdel-Mageed ${ }^{1 \#}$, Daniel Widmann ${ }^{1}$, Sine E. Olesen ${ }^{2}$, Ib Chorkendorff ${ }^{2}$, \\ and R.Jürgen Behm ${ }^{1, *}$ \\ ${ }^{1}$ Institute of Surface Chemistry and Catalysis, Ulm University, D-89069 Ulm, Germany \\ ${ }^{2}$ Department of Physics, Technical University of Denmark, DK-2800 Lyngby, Denmark
}

\begin{abstract}
Ru} / \mathrm{TiO}_{2}$ catalysts are highly active and selective in the selective methanation of $\mathrm{CO}$ in the presence of large amounts of $\mathrm{CO}_{2}$, but suffer from a considerable deactivation and loss of selectivity during time on stream. Aiming at a fundamental understanding of these processes, we have systematically investigated the physical reasons responsible for these effects, using catalysts with different surface areas and combining time resolved kinetic and in situ / operando spectroscopy measurements as well as ex situ catalyst characterization. This allowed us to identify and disentangle contributions from different effects such as structural effects, adlayer effects such as site blocking effects and changes in the chemical (surface) composition of the catalysts. Operando XANES / EXAFS measurements revealed that an initial activation phase is largely due to the reduction of oxidized Ru species, together with a distinct change in the $\mathrm{Ru}$ particle shape, until reaching a state dominated by metallic $\mathrm{Ru}$ species (fraction $\mathrm{RuO}_{2}<5 \%$ ) with the highest $\mathrm{Ru}$ mass normalized activity. The loss of activity and also of selectivity during the subsequent deactivation phase are mainly due to slow Ru particle growth (EXAFS, TEM). Surface blocking by adsorbed species such as surface formate / carbonate or surface carbon species, which are formed during the reaction, contributes little, as concluded from in situ IR, TPO and XPS data. Consequences on the selectivity for $\mathrm{CO}$ methanation, which decreases with time on stream for catalysts with larger surface area and for the distinct loss of adsorbed CO and surface formate species, as well as the role of the catalyst surface area in the reaction are discussed.
\end{abstract}

Key words: $\mathrm{CO}$ methanation, deactivation, selectivity, particle size effect, $\mathrm{Ru} / \mathrm{TiO}_{2}$, XANES, EXAFS, DRIFTS 


\section{Introduction}

The selective methanation of $\mathrm{CO}$ in $\mathrm{H}_{2}$-rich gas mixtures (SelMeth reaction) has emerged as an interesting alternative to the commonly used preferential oxidation of CO (PROX reaction) to selectively remove small amounts of $\mathrm{CO}$ from $\mathrm{H}_{2}$-rich feed gases for low-temperature polymer electrolyte fuel cells (PEFCs). Since these feed gases are often prepared by reforming of hydrocarbons or biomass, they also contain significant amounts of $\mathrm{CO}_{2}$, typically around $20 \%$, in addition to CO. Therefore, the reaction has to be highly selective for the methanation of $\mathrm{CO}$, as the methanation of $\mathrm{CO}_{2}$ would lead to intolerable losses of $\mathrm{H}_{2}$. The SelMeth reaction is particularly attractive for decentralized, small scale applications, e.g., for house (domestic) heating, where the less complicated and hence economically more feasible technology makes the SelMeth reaction an economic choice. ${ }^{1 ; 2}$

Supported Ru catalysts have turned out as the by far most active and selective catalysts for this reaction. ${ }^{3-8}$ In a series of studies we have investigated this reaction on different supported $\mathrm{Ru}$ catalysts such as $\mathrm{Ru} /$ zeolite $^{6 ; 9} \mathrm{Ru}^{\mathrm{A}} \mathrm{Al}_{2} \mathrm{O}_{3}{ }^{5 ; 10 ; 11}$ and recently on $\mathrm{Ru} / \mathrm{TiO}_{2}{ }^{12}$ In these studies we addressed mainly the interplay between the structure of these catalysts, in particular the $\mathrm{Ru}$ particle size, and their catalytic performance, both in idealized ${ }^{6 ; 9}$ and in realistic reformate gases (structure - reactivity correlations). ${ }^{10 ; 11 ; 13}$ The previous findings led to the following main conclusions: i) The inherent selectivity for $\mathrm{CO}$ methanation, at $\mathrm{CO}$ levels where the surface would be accessible also to $\mathrm{CO}_{2}$ adsorption and not blocked by $\mathrm{CO}_{\mathrm{ad}}$, is basically controlled by the size of the Ru nanoparticles (NPs), with very small Ru NPs $(<1.2 \mathrm{~nm} ø)$ being highly selective, while for larger particle size the selectivity decays quickly. This trend applies for both reducible and non-reducible supports. ii) The nature of the oxide support has a pronounced impact on the catalytic activity, with $\mathrm{Ru} /$ zeolite and $\mathrm{Ru} / \mathrm{TiO}_{2}$ being $5-8$ times more active than $\mathrm{Ru} / \mathrm{Al}_{2} \mathrm{O}_{3}$. iii) The presence of realistic amounts of water in the feed gas improves the selectivity for CO methanation by a water-assisted disruption of Ru NPs, while 
the activity decreases with increasing amount of water in the feed. ${ }^{14}$ iv) Finally, for $\mathrm{Ru} / \mathrm{TiO}_{2}$ catalysts also the support surface area was found to strongly affect the (inherent) selectivity, with the highest selectivity observed for high-surface area $\mathrm{Ru} / \mathrm{TiO}_{2}$ catalysts. $^{12}$ This was attributed to increasing metal - support interactions (MSI). This effect, which was tentatively proposed to be valid also for other Ru catalysts supported on reducible oxide supports, provides additional opportuinities for controlling the catalytic performance and in particular the selectivity for $\mathrm{CO}$ methanation of supported Ru catalysts. ${ }^{12}$

$\mathrm{Ru} / \mathrm{TiO}_{2}$ catalysts were found to be much more active than other structurally similar $\mathrm{Ru}$ catalysts (e.g., similar Ru wt.\%, Ru particle size, porosity and surface area), especially at lower methanation temperatures. ${ }^{3 ; 10 ; 12 ; 15}$ They suffer, however, from a substantial deactivation and loss of selectivity during reaction, which hinders their commercial use in the SelMeth reaction and other potential reactions. It should be underlined, however, that even after deactivation these catalysts are still significantly more active than their counterparts.

Despite of the numerous studies on the SelMeth reaction on supported $\mathrm{Ru}$ catalysts, $1 ; 3 ; 5 ; 6 ; 10 ; 11 ; 16-23$ the activation and the deactivaton of the catalyst during reaction has attracted little attention. This is even true for $\mathrm{Ru} / \mathrm{TiO}_{2}{ }^{7}$, where in contrast to $\mathrm{Ru} /$ zeolite catalysts ${ }^{5 ; 6 ; 9 ; 14}$ deactivation was significant. For the closely related Fischer-Tropsch reaction, the observed deactivation is mainly attributed to the blocking of active sites by deposition of carbon containing species. ${ }^{24-26}$ Note that the buildup of these carbon containing species was also detected at ambient pressure, not only at elevated pressures, ${ }^{27: 28}$ accordingly it may also be assumed as a possible reason for the deactivation of Ru catalysts in the SelMeth reaction, especially in the presence of large amounts of $\mathrm{CO}_{2}$ as additional carbon source. ${ }^{9}$ Nevertheless, also other effects such as structural modifications or overreduction of the catalyst cannot be excluded as physical reasons responsible for deactivation. 
In the present contribution we present results of a systematic study on the physical origin of the observed activation and deactivation of $\mathrm{Ru} / \mathrm{TiO}_{2}$ catalysts in the SelMeth reaction, which includes both losses in activity and in selectivity. This may also be helpful for a better understanding of the high catalytic activity of these catalysts and its physical origin. Studying the deactivation behavior of a set of $4 \mathrm{Ru} / \mathrm{TiO}_{2}$ catalysts with different support surface areas, but otherwise similar characteristics (same Ru loading and Ru particle sizes), and employing a multi-technique approach, we will i) try to correlate changes in the catalytic performance with dynamic changes in the catalyst structure and/or in the catalyst (surface) composition during different stages of the reaction and ii) derive systematic trends with increasing catalyst surface area. After a brief description of the experimental instrumentation and procedures (section 2), we will first focus on the activation / deactivation behavior of a specific $\mathrm{Ru} / \mathrm{TiO}_{2}$ catalyst $\left(\mathrm{Ru} / \mathrm{TiO}_{2}-1\right)$. Kinetic measurments of the (de-)activation with time on stream, and in different reaction atmospheres are combined with in situ IR spectroscopic measurements (diffuse reflection FTIR spectroscopy - DRIFTS) and operando as well as in situ (temperature programmed oxidation - TPO) and ex situ measurements for probing the chemical/electronic (by X-ray photoelectron spectroscopy - XPS and X-ray absorption near edge spectroscopy XANES) and structural (by extended X-ray absorption fine structure analysis - EXAFS, high resolution transmission electron microscopy - HR-TEM and X-ray diffraction - XRD) properties of the catalyst at different stages of the reaction, to gain information on reaction induced modifications in the catalyst structure $\left(\mathrm{Ru}, \mathrm{TiO}_{2}\right.$ particle size $)$ and in the chemical (surface) composition of the catalysts $\left(\mathrm{TiO}_{2}\right.$ phase composition, $\mathrm{Ru}$ oxidation state, $\mathrm{TiO}_{2}$ support reduction) and on the evolution of adsorbed species during reaction, especially the deposition of carbon containing species (surface formates and bicarbonates as well as surface carbon or $\mathrm{CH}_{\mathrm{x}}$ species) on the catalysts (sections 3.1 - 3.3). Afterwards we will discuss the impact of support surface area on the activation and deactivation behavior on the basis of 
similar measurements on the other 3 catalysts (section 3.4). For a more comprehensive view on the origin of catalyst activation / deactivation under realistic reaction conditions we also investigated the effect of adding substantial amounts of water in the feed gas on the (de)activation behavior (section 3.5). Finally we summarize the main results and the resulting conclusions in section 4.

\section{Experimental Section}

\subsection{Catalysts preparation and pretreatment}

The catalysts used in this study were prepared by incipient wetness impregnation, using $\mathrm{TiO}_{2}$ materials with different surface areas (see Table 1). Their preparation and details of their characterization were described elsewhere. ${ }^{12}$ Prior to the reaction, the diluted $\mathrm{Ru} / \mathrm{TiO}_{2}$ catalysts (see section 2.2) were activated in the following way: i) heating up to $150^{\circ} \mathrm{C}$ in a

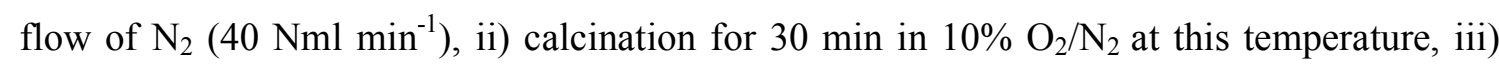
purging in $\mathrm{N}_{2}$ for $15 \mathrm{~min}$ at the same temperature, and finally iv) reduction in the respective reaction gas mixture (see Table 2) by heating up to $190^{\circ} \mathrm{C}$ in $10 \mathrm{~min}$.

Table 1: Specific surface areas and $\mathrm{Ru}$ loading of the $\mathrm{Ru} / \mathrm{TiO}_{2}$ catalysts $\mathrm{Ru} / \mathrm{TiO}_{2}-1$ -

$$
\mathrm{Ru} / \mathrm{TiO}_{2}-2
$$

\begin{tabular}{|c|c|c|c|}
\hline Catalyst & $\mathrm{TiO}_{2}$ source & $S A_{\mathrm{BET}} / \mathrm{m}^{2} \mathrm{~g}^{-1}$ & $\mathrm{Ru}$ wt. $\%$ \\
\hline $\mathrm{Ru} / \mathrm{TiO}_{2}-1$ & Degussa - Evonik & 121 & 2.24 \\
\hline $\mathrm{Ru} / \mathrm{TiO}_{2}-2$ & Sigma Aldrich & 20 & 2.08 \\
\hline $\mathrm{Ru} / \mathrm{TiO}_{2}-3$ & Degussa - Evonik & 64 & 2.17 \\
\hline $\mathrm{Ru} / \mathrm{TiO}_{2}-4$ & Sachtleben & 235 & 2.76 \\
\hline
\end{tabular}

According to previous XPS and energy dispersive X-ray (EDAX) characterization the calcination procedure is sufficient to minimize the residual $\mathrm{Cl}$ from the sample after 
preparation to very low and similar concentration on all prepared samples, while keeping the thermal load of the catalyst at a minimum (see ref. ${ }^{12}$ ).

\subsection{Kinetic measurements}

The kinetic measurements were carried out in a fixed bed micro-reactor at atmospheric pressure using high purity gases (99.999\%) supplied by Westfalen AG. The gas mixtures indicated in Table 2 were prepared using mass flow controllers from Hastings (HFC-202)

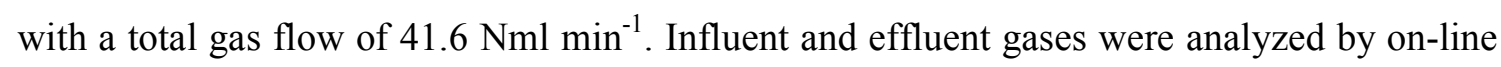
gas chromatography (GC) with a CO detection limit of ca. 10 ppm (DANI 86.10), where $\mathrm{H}_{2}$ is used as carrier gas. All results were obtained under differential reaction conditions (CO conversion $\leq 20 \%$ ) by diluting the catalysts with thermally stable and catalytically inactive $\alpha$ $\mathrm{Al}_{2} \mathrm{O}_{3}$ (calcined at $1200^{\circ} \mathrm{C}$ for 24 hours) to form a catalyst bed of $\sim 1.2 \mathrm{~cm}$ length $(\sim 200 \mathrm{mg})$. The fixed size of the catalyst bed and the identical gas flow ensured a constant space velocity in all experiments. For the first GC measurement, the reaction gas was sampled after 10 min, to allow for a stabilization of the reaction gas composition, subsequently samples were taken every $15 \mathrm{~min}$.

Table 2: Composition of the different reaction gas mixtures used in the kinetic and spectroscopic measurements.

\begin{tabular}{|c|c|c|c|}
\hline \multirow{2}{*}{ Reaction reformate } & \multicolumn{3}{|c|}{ Reaction gas composition } \\
\cline { 2 - 4 } & $\mathrm{CO} / \mathrm{ppm}$ & $\mathrm{CO}_{2} / \%$ & $\mathrm{~N}_{2} / \%$ \\
\hline ID-ref 6000 & 6000 & 0.0 & 3.0 , balance $\mathrm{H}_{2}$ \\
\hline SR-ref 6000 & 6000 & 15.5 & 3.0 , balance $\mathrm{H}_{2}$ \\
\hline SR-ref 100 & 100 & 15.5 & 3.0 , balance $\mathrm{H}_{2}$ \\
\hline
\end{tabular}

The $\mathrm{Ru}$ mass-normalized reaction rate $\mathrm{r}_{\mathrm{CO}}$ for $\mathrm{CO}$ methanation was calculated according to equation (1), using the $\mathrm{CO}$ conversion $\left(\mathrm{X}_{\mathrm{CO}}\right)$ under differential reaction conditions $\left(\mathrm{X}_{\mathrm{CO}}<\right.$ 
$20 \%$, see above), the molar flow rate of CO into the reactor $\left(\dot{\mathrm{n}}_{\mathrm{CO}, \text { in }}\right)$, and the absolute mass of $\mathrm{Ru}$ metal $\left(\mathrm{m}_{\mathrm{Ru}}\right)$. The $\mathrm{Ru}$ mass-normalized $\mathrm{CH}_{4}$ formation rate, in contrast, was calculated from the effluent molar flow rate of $\mathrm{CH}_{4}$ formed ( $\dot{\mathrm{n}}_{\mathrm{CH} 4 \text {,out }}$ ), which is produced from $\mathrm{CO}$ and $\mathrm{CO}_{2}$ (equation (2)). From these $\mathrm{Ru}$ mass-normalized reaction rates, the turnover frequencies (TOFs) were calculated, using the molar mass of $\mathrm{Ru}\left(\mathrm{M}_{\mathrm{Ru}}\right)$ and the $\mathrm{Ru}$ dispersion $\left(\mathrm{D}_{\mathrm{Ru}}\right)$ obtained from the EXAFS measurements, according to equation (3). The selectivity towards $\mathrm{CO}$ methanation $\left(\mathrm{S}_{\mathrm{CO}}\right)$ is given by the ratio of the $\mathrm{CO}$ methanation rate divided by the overall methane formation rate (from $\mathrm{CO}$ and $\mathrm{CO}_{2}$, see equation 4). The deactivation (De.\%) of the catalyst for $\mathrm{CO}$ methanation was calculated as the difference between the highest reaction rate $\left(r_{\max }\right)$ during the measurement and the reaction rate at the respective reaction times $\left(r_{t}\right)$, normalized by the maximum rate $\left(\mathrm{r}_{\max }\right)$.

$$
\begin{aligned}
& r_{C O}=\frac{X_{C O} \times \dot{n}_{C O, \text { in }}}{m_{R u}} \\
& r_{C H 4}=\frac{\dot{n}_{C H 4, \text { out }}}{m_{R u}} \\
& T O F_{C O}=\frac{r_{C O} \times M_{R u}}{D_{R u}} \\
& S_{C O}=\frac{r_{C O}}{r_{C H 4}}=\frac{r_{C O}}{r_{C O}+r_{C O 2}} \times 100 \\
& \text { De. \% }=\frac{r_{\text {max }}-r_{t}}{r_{\text {max }}} \times 100
\end{aligned}
$$

2.3 In situ IR spectroscopy measurements: In situ diffuse reflectance Fourier transform infrared spectroscopy (DRIFTS) measurements were carried out using a commercial in situ reaction cell (Harricks, HV-DR2). The spectra were recorded using a Magna 6700 spectrometer (Thermo-Fischer) equipped with a MCT narrow-band gap detector. Background spectra were recorded in a flow of $\mathrm{N}_{2}$ at $150^{\circ} \mathrm{C}$ directly after the pretreatment. Afterwards, the catalysts were heated up in the respective reaction gas mixture as described for the kinetic measurements. After starting the reaction, spectra with a high time resolution, with 20 scans 
per spectrum (data acquisition: $15 \mathrm{sec}$, one spectrum every $15 \mathrm{sec}$ ), were recorded during the first $10 \mathrm{~min}$ in order to follow rapid changes in the catalyst surface (first spectrum started $5 \mathrm{~s}$ after starting the reaction). After 15 min, we changed to a lower time resolution with better signal-to-noise, averaging over 400 scans per spectrum (data acquisition $200 \mathrm{sec}$, one spectrum every $250 \mathrm{sec}$ ). All DRIFTS spectra are presented in Kubelka-Munk units (KMU), whose intensities are generally considered to be proportional to the coverage of the respective surface species.

\subsection{Chemical and structural characterization}

2.4.1 X-ray photoelectron spectroscopy (XPS): XP spectra were recorded on a PHI 5800 ESCA system (Physical Electronics), using monochromatized Al- $\mathrm{K}_{\alpha}$ radiation $(1486 \mathrm{eV})$ and a detection angle of $45^{\circ}$ with respect to the surface normal. Spectra were recorded after reaction in a SR-ref 6000 gas mixture at $190{ }^{\circ} \mathrm{C}$ for 10 and 1000 min respectively. The binding energies (BEs) were calibrated using the $\mathrm{C}(1 \mathrm{~s})$ peak of adventitious carbon at $284.4 \mathrm{eV}$ as reference. The Ru:Ti surface ratios were calculated from the measured intensities of the $R u(3 d)$ and Ti(2p) signals, using tabulated atomic sensitivity factors.

2.4.2 X-ray diffraction (XRD): XRD measurements were performed on a Siemens D5000 diffractometer after 10 and $1000 \mathrm{~min}$ of reaction in ID-ref 6000 reformate, using $\mathrm{Cu} \mathrm{K}_{\alpha}$ radiation $(\lambda=0.154 \mathrm{~nm})$. The average $\mathrm{TiO}_{2}$ crystallite sizes in the respective catalysts were calculated from the width of the diffraction peak of anatase at $2 \Theta=25.373^{\circ}$ via the Scherrer equation. The ratio of anatase / rutile was also estimated from the diffractograms, taking the relative intensities of the diffraction peaks at $25.373^{\circ}\langle 101\rangle$ for anatase, and $27.522^{\circ}\langle 110\rangle$ for rutile.

2.4.3 Transmission electron microscopy (TEM): The sizes, size distributions and shapes of the Ru NPs were determined from HR-TEM micrographs taken after reaction in SR-ref 6000 
reformate for different times on stream $(10,590$ and $1000 \mathrm{~min})$ at $190{ }^{\circ} \mathrm{C}$. The catalyst particles were deposited by drop coating onto carbon grids. The TEM measurements were performed on a Philips CM 20 instrument operated at $200 \mathrm{kV}$. For detailed information on the $\mathrm{Ru}$ particle size distribution, at least 600 particles were evaluated for each sample.

\subsubsection{X-ray absorption spectroscopy (XAS): Time resolved operando XANES and EXAFS} measurements were performed in the transmission mode at the XAFS beamline of the Elettra synchrotron, using a Si-311 double crystal monochromator. The spot size illuminated by the X-ray beam was roughly $6 \mathrm{~mm}$ vertical and $2 \mathrm{~mm}$ horizontal. A specially designed reaction cell was used for the in situ XAS measurements. ${ }^{6 ; 9}$ A catalyst bed of $50 \mathrm{mg}$ of $\mathrm{Ru} / \mathrm{TiO}_{2}$ diluted with $\mathrm{SiO}_{2}\left(2: 1\right.$ - roughly $\left.33 \mathrm{mg} \mathrm{Ru} / \mathrm{TiO}_{2}\right)$ was loaded in the reaction cell. Note that the amount of catalyst is roughly 2 times larger than the amount used in kinetic measurements to allow for reasonable signal-to-noise ratio (for conversions see Fig. S1 in the Supporting Information). The spectra were collected in transmission mode at the Ru K-edge $(22117 \mathrm{eV})$, using two $\mathrm{Ar} / \mathrm{N}_{2}$ filled ionization chambers for detection. A ruthenium metal foil placed in between the second and an additional ionization chamber allowed for simultaneous internal calibration during all experiments. The pre-edge region was measured from 21867 to 22087 $\mathrm{eV}$ with a step size of $10 \mathrm{eV}$. For the XANES region region (22087 - $22157 \mathrm{eV})$ and for the EXAFS region $(22157-23317 \mathrm{eV})$ we used step widths of 0.5 and $0.98 \mathrm{eV}$. The data acquisition in the XANES region took 5 min per spectrum, while for the EXAFS spectra this took about $30 \mathrm{~min}$. A $\mathrm{Ru}$ foil and a pellet of $\mathrm{Ru}$ (IV) oxide, which were measured in transmission, were used as reference materials for the data evaluation. Background subtraction and spectra normalization as well as the linear combination analysis (LCA) of the XANES spectra were performed using the Athena software from the IFEFFIT program package. ${ }^{29 ; 30}$ Based on the linear combination analysis of the XANES spectra the fraction of oxidized / reduced $\mathrm{Ru}$ nanoparticles was obtained by determining the contribution of the 
respective reference spectra to the catalyst / reaction spectra. ${ }^{29 ; 31}$ The data reduction and subsequent fits of EXAFS spectra were carried out using the XDAP software package with standard procedures, as described elsewhere. ${ }^{32}$ Assuming a hcp structure, theoretical references were calculated by FEFF 8.0, and calibrated with experimental references of Ru foil and $\mathrm{RuO}_{2}$ powder. ${ }^{33 ; 34}$ All XANES / EXAFS measurements were performed in ID-ref 6000 reaction gas mixture (see Table 2).

The EXAFS data were evaluated in the R-space (R: $0.0-4.5 \AA$ ), using the k-range from 3.2 $11.8 \AA^{-1}$. In the EXAFS data fit we allowed the coordination number $(\mathrm{CN})$, the Debye-Waller factor (DWF), the Ru-Ru bond length (R), and the energy shift $\left(\mathrm{E}_{0}\right)$ to change freely.

2.4.5 Temperature programmed oxidation (TPO): To detect the amount of oxidizable carbon on the catalyst surface at different stages of the reaction, TPO measurements were performed directly after reaction in the same reactor. After purging for $1000 \mathrm{~min}$ in a stream of $\mathrm{N}_{2}$ at $190^{\circ} \mathrm{C}$, we first performed an additional temperature programmed desorption (TPD) run (in $\mathrm{N}_{2}$, from $190^{\circ} \mathrm{C}$ to $450^{\circ} \mathrm{C}: 9^{\circ} \mathrm{C} \mathrm{min}^{-1}$ ) to remove surface carbonates and formate. Subseequently, the gas flow was switched to $10 \% \mathrm{O}_{2} / \mathrm{N}_{2}\left(35 \mathrm{NmL} \mathrm{min}^{-1}\right)$ and the temperature was continuously increased from $190^{\circ} \mathrm{C} \min ^{-1}$ to $450{ }^{\circ} \mathrm{C}\left(9^{\circ} \mathrm{C} \mathrm{min}{ }^{-1}\right)$. The resulting $\mathrm{CO}_{2}$ and $\mathrm{CO}$ concentrations in the effluent gas were monitored continuously by IR transmission spectroscopy, using an analyzer set-up combining a shoe-box sized Bruker Alpha FTIR spectrometer (Bruker Optics Inc., Germany) and a customized integrated hollow-waveguide (iHWG). ${ }^{35}$ All TPO measurement were performed in ID-ref 6000 reaction gas mixture (see Table 2).

\section{Results and discussion}

\subsection{Activation / deactivation during CO methanation}


We first followed the catalytic activity of the $\mathrm{Ru} / \mathrm{TiO}_{2}-1$ catalyst in reformate gases with medium CO concentrations (6000 ppm), both in the presence (SR-ref 6000) and in the absence (ID-ref 6000) of $\mathrm{CO}_{2}$ (see Table 2). In the latter case, interaction of $\mathrm{CO}_{2}$ with the support is avoided as well. In SR-ref 6000 , the selectivity for CO methanation was found to be always $100 \%$. By comparing with findings for a $\mathrm{Ru} /$ zeolite catalyst, we attribute this to site blocking for $\mathrm{CO}_{2}$ adsorption by adsorbed $\mathrm{CO}$, which completely covers the Ru NPs. ${ }^{6}$

Fig. 1a illustrates the temporal evolution of the $\mathrm{Ru}$ mass normalized $\mathrm{CH}_{4}$ formation rate during the reaction in SR-ref 6000 gas mixture, which at 100\% selectivity (see above) is equal to the $\mathrm{CO}$ methanation rate, and the corresponding deactivation. In the initial phase, the activity increased continuously from $5.2 \times 10^{-6} \mathrm{~mol}_{\mathrm{CH} 4} \mathrm{~g}_{\mathrm{Ru}}{ }^{-1} \mathrm{~s}^{-1}$ after $10 \mathrm{~min}$, until it reached its maximum value of $31.8 \times 10^{-6} \mathrm{~mol}_{\mathrm{CH} 4} \mathrm{~g}_{\mathrm{Ru}}{ }^{-1} \mathrm{~s}^{-1}$ after $120 \mathrm{~min}$. After this activation phase, the

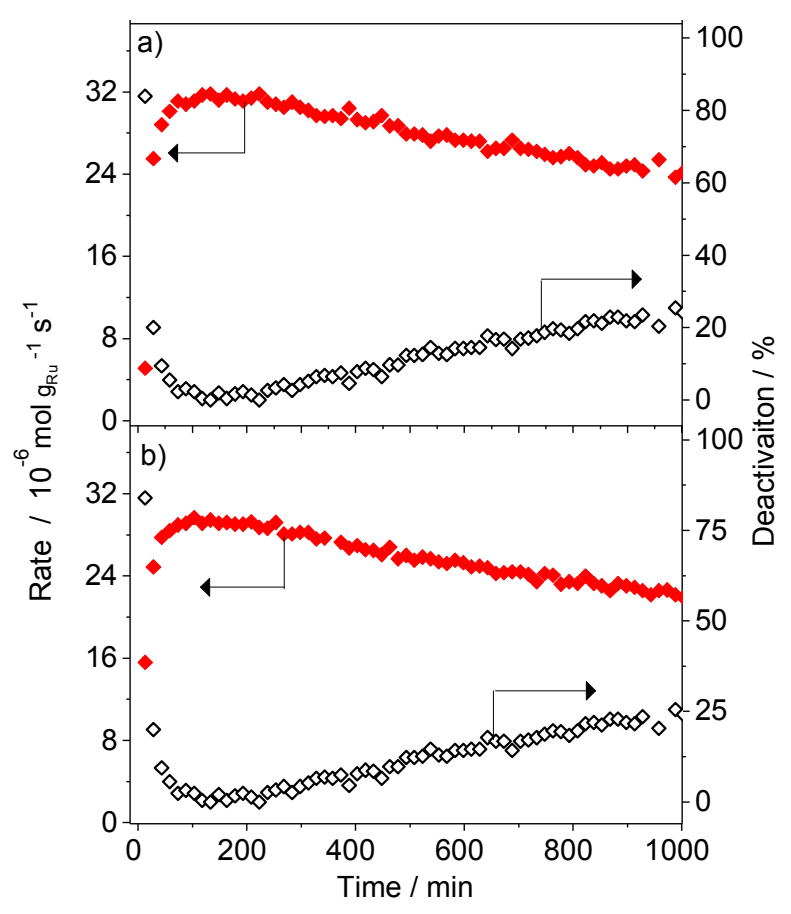

Figure 1 Ru mass normalized CO methanation rates $(\diamond)$ and corresponding deactivation $(\diamond)$ for the $\mathrm{Ru} / \mathrm{TiO}_{2}-1$ catalyst in SR-ref 6000 (a) and in ID-ref 6000 (b) during reaction at $190^{\circ} \mathrm{C}$. 
rate started to decrease continuously, reaching a value of $24.0 \times 10^{-6} \mathrm{~mol}_{\mathrm{CH} 4} \mathrm{~g}_{\mathrm{Ru}}{ }^{-1} \mathrm{~s}^{-1}$ after 1000 min. This represents a deactivation of $24 \%$ over 1000 min relative to the maximum activity, which was reached at $120 \mathrm{~min}$ (see Table 3). It should be noted that in both gas mixtures the $\mathrm{CH}_{4}$ methane formation rate is identical to the $\mathrm{CO}$ methanation rate under these conditions. In ID-ref 6000 reformate, in the absence of $\mathrm{CO}_{2}$ (Fig. 1b), the reaction behavior was rather similar, with only small differences in the absolute values of the Ru mass normalized activity. After 10 min the rate was $15.6 \times 10^{-6} \mathrm{~mol}_{\mathrm{CH} 4} \mathrm{~g}_{\mathrm{Ru}}{ }^{-1} \mathrm{~s}^{-1}$ and reached its maximum value $\left(30.5 \times 10^{-}\right.$ ${ }^{6} \mathrm{~mol}_{\mathrm{CH} 4} \mathrm{~g}_{\mathrm{Ru}}{ }^{-1} \mathrm{~s}^{-1}$ ) also after $\sim 120 \mathrm{~min}$. Intuitively, one would expect a lower deactivation in the absence of $\mathrm{CO}_{2}$ compared to that measured in SR-ref 6000 (Fig. 1a), since $\mathrm{CO}_{2}$ is known to be one of the main sources of deactivation during hydrogenation reactions, due to the formation of surface formates and / or bi-carbonates. ${ }^{9 ; 36 ; 37}$. In the present case, however, the magnitude of the deactivation was almost identical in both reformate gas mixtures (see Table 3), indicating that under present reaction conditions, the interaction of $\mathrm{CO}_{2}$ with the $\mathrm{Ru} / \mathrm{TiO}_{2}$ catalyst cannot be responsible for the observed deactivation. This will be investigated in more detail later (see section 3.2).

Table 3 Maximum and final CO methanation rates after $1000 \mathrm{~min}\left(\mathrm{r}_{800}\right)$ and after deactivation in SR-ref 6000 and ID-ref 6000 reformate gas mixtures, respectively, for different $\mathrm{Ru} / \mathrm{TiO}_{2}$ catalysts.

\begin{tabular}{|c|c|c|c|c|c|c|}
\hline \multirow{2}{*}{ Catalyst } & \multicolumn{3}{|c|}{$\begin{array}{c}\text { CO methanation } / 10^{-6} \mathrm{~mol} \mathrm{~g}_{\mathrm{Ru}}{ }^{-1} \mathrm{~s}^{-1} \\
\text { (SR-ref 6000) }\end{array}$} & \multicolumn{3}{|c|}{ CO methanation $/ 10^{-6} \mathrm{~mol}_{\mathrm{Ru}^{-1}} \mathrm{~s}^{-1}$} \\
\cline { 2 - 7 } & $\mathrm{r}_{\max }$ & $\mathrm{r}_{1000}$ & $\begin{array}{c}\text { Deactivation } \\
/ \%\end{array}$ & $\mathrm{r}_{\max }$ & $\mathrm{r}_{\mathrm{d}}$ & $\begin{array}{c}\text { Deactivation } \\
/ \%\end{array}$ \\
\hline $\mathrm{Ru} / \mathrm{TiO}_{2}-1$ & 31.8 & 24.2 & 23.9 & 30.5 & 26.4 & 23 \\
\hline $\mathrm{Ru} / \mathrm{TiO}_{2}-2$ & 4.10 & 2.30 & 43.9 & 5.90 & 3.30 & 44.1 \\
\hline $\mathrm{Ru} / \mathrm{TiO}_{2}-3$ & 26.0 & 19.8 & 23.8 & 19.6 & 13.2 & 32.7 \\
\hline $\mathrm{Ru} / \mathrm{TiO}_{2}-4$ & 12.5 & 10.2 & 18.4 & 10.6 & 8.30 & 21.7 \\
\hline
\end{tabular}

* $\mathrm{R}_{\max }$ Maximum activity attained during reaction 
For comparison, we furthermore investigated the reaction behavior of a reaction gas mixture with a much lower $\mathrm{CO}$ concentration (100 ppm, SR-ref 100 reformate). Based on previous work on $\mathrm{Ru} /$ zeolite catalysts performed under identical conditions, the $\mathrm{CO}_{\mathrm{ad}}$ coverage is far below saturation under these conditions, ${ }^{5}$ which allows for testing the intrinsic activity of the $\mathrm{Ru} \mathrm{NP}$ catalyst for the $\mathrm{CO}_{2}$ methanation, in the absence of a $\mathrm{CO}_{\mathrm{ad}}$ blocking layer. Fig. 2 shows the time evolution of the activity / deactivation and the selectivity for CO methanation. Similar to reaction in the $6000 \mathrm{ppm}$ CO gas mixtures, the activity for CO methanation passed through an initial activation phase, before it decreased again. The maximum activity was reached, however, significantly earlier and the rate was much higher, increasing from $31.0 \times 10^{-6} \mathrm{~mol}_{\mathrm{CH} 4} \mathrm{~g}_{\mathrm{Ru}}{ }^{-1} \mathrm{~s}^{-1}$ after $10 \mathrm{~min}$ to $65.0 \times 10^{-6} \mathrm{~mol}_{\mathrm{CH} 4} \mathrm{~g}_{\mathrm{Ru}}{ }^{-1} \mathrm{~s}^{-1}$ at $75 \mathrm{~min}$, pointing to a negative reaction order for $\mathrm{CO}$ at higher $\mathrm{CO}$ concentrations, as it was also reported for $\mathrm{Ru} /$ zeolite and $\mathrm{Ru} / \mathrm{Al}_{2} \mathrm{O}_{3}$ catalysts. ${ }^{5}$ The earlier reaching of the maximum may be related to the fact that the catalyst dilution was significantly higher in this gas mixture. After 1000 min

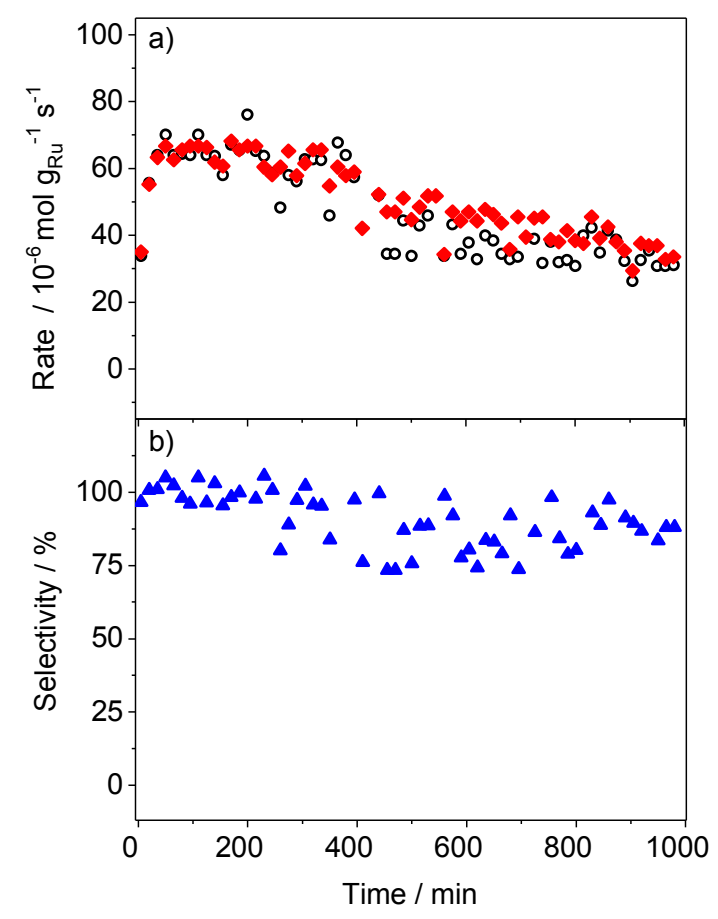

Figure 2 a) Activity ( $\diamond: \mathrm{CH}_{4}$ formation; ○: $\mathrm{CO}$ methanation) and b) selectivity ( $\left.\mathbf{\Delta}\right)$ during the selective $\mathrm{CO}$ methanation in SR-ref 100 at $190^{\circ} \mathrm{C}$ over the $\mathrm{Ru} / \mathrm{TiO}_{2}-1$ catalyst. 
on stream, the rate had decreased to $24.2 \times 10^{-6} \mathrm{~mol}_{\mathrm{CH} 4} \mathrm{~g}_{\mathrm{Ru}}{ }^{-1} \mathrm{~s}^{-1}$ (see table 3). The selectivity for CO methanation remained stable at $100 \%$ during the first $400 \mathrm{~min}$, while for longer reaction times it decreased slowly, but continuously, to reach $\sim 89 \%$ after 1000 min on stream.

\subsection{Adlayer formation and changes during selective $\mathrm{CO}$ methanation}

In Fig. 3 we present DRIFTS spectra recorded during CO methanation at $190^{\circ} \mathrm{C}$ in a SR-ref 6000 gas mixture on the $\mathrm{Ru} / \mathrm{TiO}_{2}-1$ catalyst (left panels; Fig. 3a) and on the pure $\mathrm{TiO}_{2}-1$ support, respectively (right panels; Fig. 3c). On the catalyst the spectra resolve a number of different modes related to $\mathrm{CO}$ adsorbed on the surface of the Ru NPs (see also ${ }^{12}$ ). Bands at 2135 and $2078 \mathrm{~cm}^{-1}$ were previously attributed to $\mathrm{CO}$ coadsorbed with $\mathrm{O}_{\mathrm{ad}}$ or to $\mathrm{CO}_{\mathrm{ad}}$ at the Ru-oxide interface, possibly with multiply bonded carbonyl species, respectively. ${ }^{38-40}$ The band at around $2060 \mathrm{~cm}^{-1}$ was associated with $\mathrm{CO}$ adsorbed on top sites of the Ru NPs. Finally, the bands at $2009 \mathrm{~cm}^{-1}$ and $1982 \mathrm{~cm}^{-1}$ were likely also due to on top adsorbed $\mathrm{CO}_{\mathrm{ad}}$ species at different sites of the Ru NPs or on very small Ru NPs. ${ }^{41}$ Leaving the $\mathrm{CO}_{\mathrm{ad}}$ regime, a weak band at $1765 \mathrm{~cm}^{-1}$ is attributed to formyl surface species $\left(\mathrm{HCO}_{\mathrm{ad}}\right),{ }^{18}$ and the band at $1556 \mathrm{~cm}^{-1}$ is associated with either surface formate or surface bicarbonate $\left(\mathrm{HOCO}_{2, \mathrm{ad}}\right)$ species. ${ }^{40 ; 42}$ Comparison with the bare $\mathrm{TiO}_{2}-1$ support shows that there are no peaks in the $\mathrm{CO}_{\mathrm{ad}}$ region, while the formate / bicarbonate related band at $1556 \mathrm{~cm}^{-1}$ was present also on the bare support material (see Fig. 3a). Interestingly, in both cases the initial and the final intensity of this band were essentially identical (Fig. 3c). Evidently, these species are formed on the $\mathrm{TiO}_{2}$ surface rather than on the Ru NPs, and the formation rate is not enhanced by the presence of the Ru NPs.

Similar measurements were preformed in an ID-ref 6000 reformate gas mixture. In this case we particularly wanted to evaluate the extent of carbon-containing surface species formed upon the interaction of the catalyst / catalyst support with the $\mathrm{CO} / \mathrm{H}_{2}$ mixture in the absence 
of $\mathrm{CO}_{2}$. The spectra collected on the $\mathrm{Ru} / \mathrm{TiO}_{2}-1$ catalyst (see Fig. $3 b$ ) showed similar features in the $\mathrm{CO}$ stretch region as in the SR-ref 6000 gas mixture, while the weak formate (bicarbonate) related band at $1556 \mathrm{~cm}^{-1}$ is much lower than in the latter case, with intensities close to noise level, both on the catalyst (Fig. 3b) and on the $\mathrm{TiO}_{2}-1$ support (Fig. 3d).

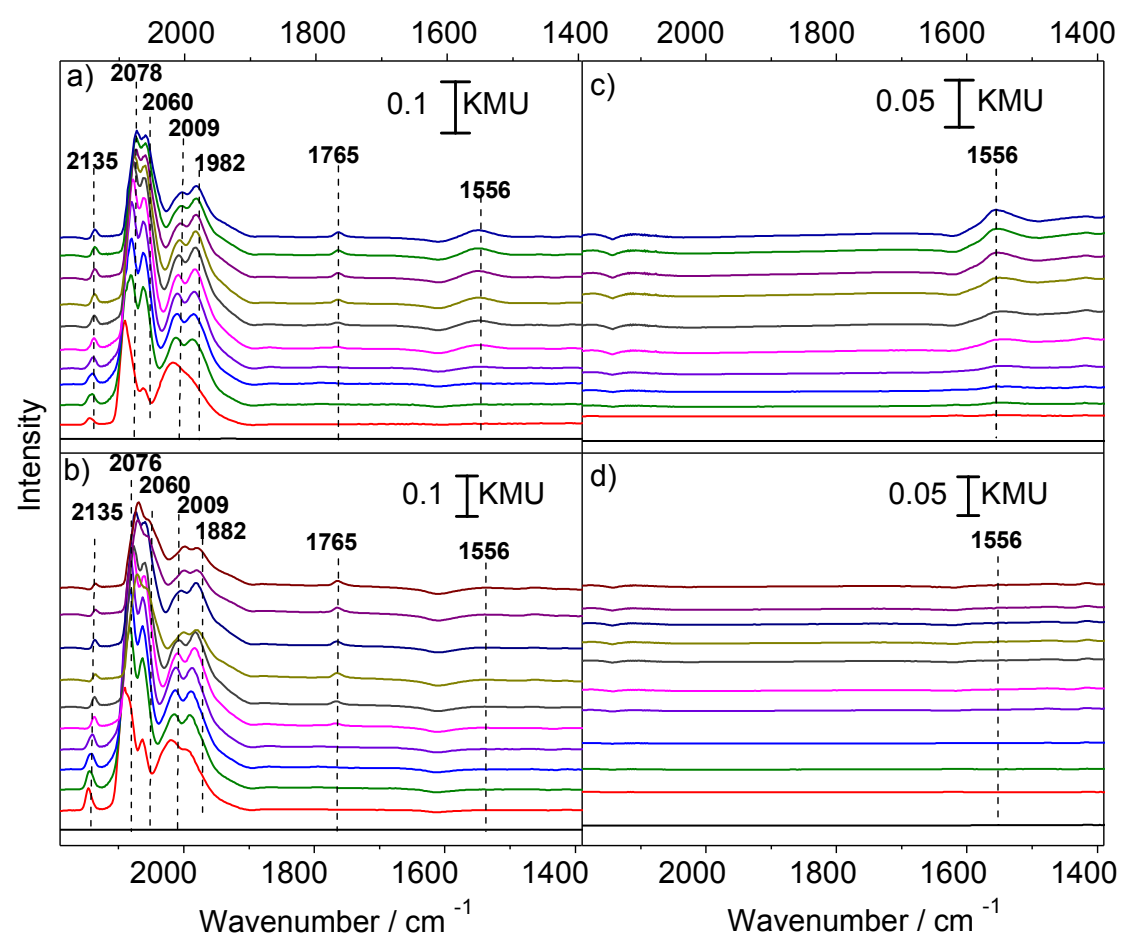

Figure 3 Series of in situ time-resolved DRIFTS spectra measured on the $\mathrm{Ru} / \mathrm{TiO}_{2}-1$ catalyst (left panels: a,b) and on the bare $\mathrm{TiO}_{2}-1$ support (right panels: c,d) in SRref $6000(\mathrm{a}, \mathrm{c})$ and in ID-ref $6000(\mathrm{~b}, \mathrm{~d})$ reformate gas mixtures (from bottom to top: $0,1,5,7,15,35,105,195,495,645$, and $795 \mathrm{~min}$, reaction temperature $\left.190^{\circ} \mathrm{C}\right)$.

To quantify the changes in the band intensities and thus in the coverages of the respective species during the reaction, we plotted the respective band intensities as a function of time on stream. Fig. 4.a shows the temporal evolution of different $\mathrm{CO}_{\mathrm{ad}}$ bands / Ru-carbonyl species over $800 \mathrm{~min}$ in the SR-ref 6000 reformate gas mixture. Similar to the activity behavior in the kinetic measurements the coverage of these species first increases, followed by a continuous decay with time. In some cases, steady-state conditions are reached after between 600 and 800 
min, in others not. Interestingly, the initial 'activation phase' is much shorter than in the kinetic measurements, ca. $30 \mathrm{~min}$ as compared to $120 \mathrm{~min}$, despite the identical reaction conditions.

For a quantitative correlation with the deactivation we calculated the relative decrease of the different band intensities during time on stream relative to the maximum intensity. The resul

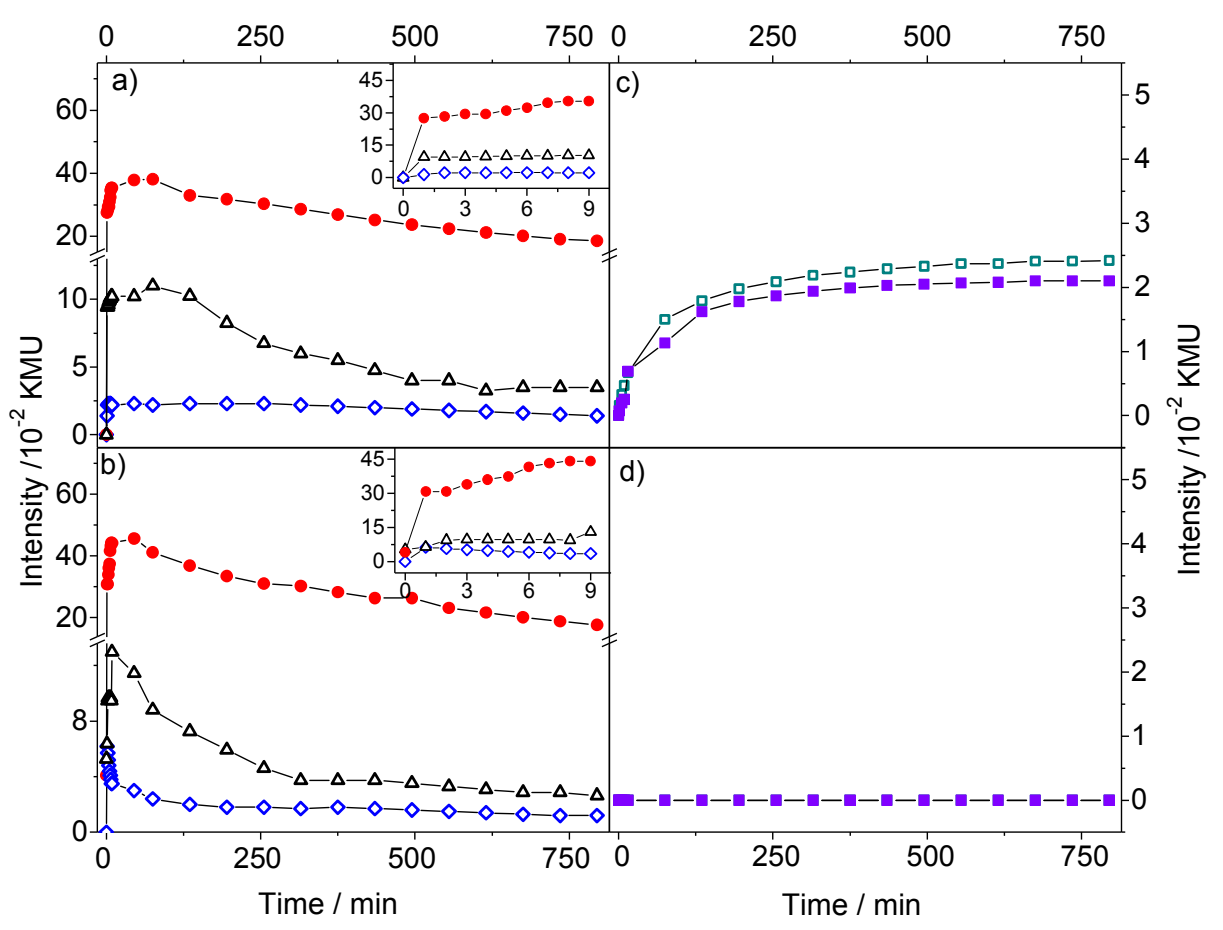

Figure 4 a,b) Time evolution of the intensity of different $\mathrm{CO}_{\mathrm{ad}}$ and Ru-carbonyl species $(\diamond$ : $\left.2135 \mathrm{~cm}^{-1} ; \bullet: 2078 \mathrm{~cm}^{-1} ; \Delta: 2009\right)$ during selective methanation on the $\mathrm{Ru} / \mathrm{TiO}_{2}-1$ catalyst in SR-ref 6000 (a)) and in ID-ref 6000 reformate gas mixtures (b). c,d) Time evolution of the intensity of the surface formate related band $\left(1556 \mathrm{~cm}^{-1}\right)$ on the bare $\mathrm{TiO}_{2}$ support (empty symbol) and on the $\mathrm{Ru} / \mathrm{TiO}_{2}-1$ catalyst (filled symbol) in SR-ref 6000 (c) and in ID-ref 6000 reformate gas mixture (d). Insets $(\mathrm{a}, \mathrm{b})$ shows the time evolution of the Ru-carbonyl $\mathrm{CO}$ band intensity during the first $10 \mathrm{~min}$.

ting values are around $40 \%$ for the Ru-carbonyl at $2078-2085 \mathrm{~cm}^{-1}$, and $43 \%$ for the $\mathrm{Ru}$ carbonyl at $2135 \mathrm{~cm}^{-1}$, while it was $39 \%$ for on top adsorbed $\mathrm{CO}_{\mathrm{ad}}\left(2009 \mathrm{~cm}^{-1}\right)$. Essentially, the decay of the $\mathrm{CO}_{\mathrm{ad}}$ related IR band intensities is around $40 \%$, independent of the type. For 
comparison, the deactivation after $800 \mathrm{~min}$ on stream was about $20 \%$. Possible correlations between deactivation and decay in the coverage of adsorbed species will be discussed later (section 3.3).

Similar DRIFTS measurements performed in the ID-ref 6000 reformate gas mixture, in the absence of $\mathrm{CO}_{2}$, led to the following results (see Fig. 4b): First of all, essentially the same species are formed, and also the general accumulation behavior is similar as in SR-ref 6000 . The maximum intensities are generally reached in a shorter time compared to reaction in SRref 6000 , within few minutes, and also the loss in relative intensity after $800 \mathrm{~min}$ is more pronounced. The relative intensity loss in this case is $44 \%$ and $72 \%$ for the two different $\mathrm{Ru}$ carbonyls at $2078-2085 \mathrm{~cm}^{-1}$ and at $2135 \mathrm{~cm}^{-1}$, and $66 \%$ for on top adsorbed $\mathrm{CO}_{\mathrm{ad}}\left(2009 \mathrm{~cm}^{-}\right.$ $1)$.

Comparing the time evolution of the band intensities of the surface formate species on the $\mathrm{Ru} / \mathrm{TiO}_{2}-1$ catalyst and on the pure $\mathrm{TiO}_{2}-1$ support in the SR-ref 6000 gas mixture (see Fig. 4), we find that this is almost identical in both cases. The coverage of these species increases steadily during the first $400 \mathrm{~min}$ and then seems to saturate. After $400 \mathrm{~min}$ it reached about $95 \%$ of the final value obtained after 800 min on stream. In this case, the discrepancy between decay of the band intensity and deactivation is even more pronounced than for the $\mathrm{CO}_{\mathrm{ad}}$ coverage. For reaction in ID-ref 6000 the intensities were too low to be evaluated, although kinetic measurements showed a sizeable deactivation (24\%) also in this case.

Another side product of methanation reactions often reported in the literature are carbon or adsorbed $\mathrm{CH}_{\mathrm{x}}$ deposits, that may block the Ru NP surface for reaction. In order to test for the formation of these species, we performed TPO measurements on the $\mathrm{Ru} / \mathrm{TiO}_{2}-2$ catalyst with the lowest surface area $\left(20 \mathrm{~m}^{2} \mathrm{~g}^{-1}\right)$, which showed the highest deactivation (see section 3.1 ). To determine possibe background contributions, we first performed a TPO measurement on a catalyst sample that after calcination was activated for $10 \mathrm{~min}$ at $190^{\circ} \mathrm{C}$ in ID-ref 6000 gas 
mixture. In a second measurement, we used a sample after 1000 min on stream. The TPO spectra (see Fig. S2, Supporting Information) show that in both cases there was very little $\mathrm{CO}_{2}$ evolution and no measurable $\mathrm{CO}$ formation during the TPO measurement. After background subtraction, the total amount of oxidizable carbon on the surface after $1000 \mathrm{~min}$ on stream corresponds to about $2.5 \%$ of a monolayer, assuming a dispersion of $48 \%$ for the $\mathrm{Ru}$ NPs (see section 3.4) and that all of this carbon is adsorbed on the surface of the Ru NPs. The extent of surface site blocking by adsorbed carbon species is far below the deactivation over 1000 min on stream of $44 \%$ measured for this catalyst (section 3.1 ).

These findings in total indicate that under present reaction conditions site blocking by $\mathrm{CO}_{\mathrm{ad}}$ or by reaction intermediates / reaction side products is not mainly responsible for the observed deactivation, but at most a minor contribution. Other possible reasons could be structural or chemical modifications such as a change of Ru NPs dispersion or of the catalyst surface composition with time, which would fit to the decaying intensity of adsorbed CO. This will be explored in the next section.

\subsection{Reaction induced changes of $\mathrm{Ru} / \mathrm{TiO}_{2}$ catalyst}

In this part we focus on reaction induced changes in the chemical / electronic and structural properties of the $\mathrm{Ru} / \mathrm{TiO}_{2}-1$ catalyst due to the interaction with the reaction gas mixture. We will first characterize changes in the chemical / electronic properties of the Ru NPs and the $\mathrm{TiO}_{2}$ crystallites during the reaction employing XANES and XPS measurements. Subsequently, structural modifications will be evaluated based on time resolved operando EXAFS and ex situ HR-TEM and XRD measurements.

\subsubsection{Reaction induced chemical modifications - Reduction of $\mathrm{Ru}$ and $\mathrm{TiO}_{2}$ particles}

Time resolved operando XANES measurements were performed after pretreatment and subsequent heat-up in ID-ref 6000 reaction gas, while CO methanation was simultaneously 
followed by GC (see Fig. S1, Supporting Information). The spectra were evaluated by applying a linear combination analysis (LCA) in order to quantify the contribution of oxidized and metallic $\mathrm{Ru}$ species in the catalyst (see Fig. S3, Supporting Information), using additionally measured spectra of $\mathrm{RuO}_{2}$ and of a $\mathrm{Ru}$ foil as references. . $^{3 ; 43 ; 44}$

The general appearance of the spectrum in Fig. 5 with its characteristic broad peak in the range of $22115 \mathrm{eV}-22140 \mathrm{eV}$ closely resembles that of $\mathrm{RuO}_{2}$ (see spectrum for $\mathrm{RuO}_{2}$ in Fig. $\mathrm{S} 3$, Supporting Information), indicating that after calcination in $10 \% \mathrm{O}_{2} / \mathrm{N}_{2}$ at $150{ }^{\circ} \mathrm{C}$ the catalyst is in an almost fully oxidized state. This is confirmed by the LCA analysis, which reveals a dominant oxidic contribution $(96 \pm 1 \%)$ with a very small fraction of metallic $\mathrm{Ru}$

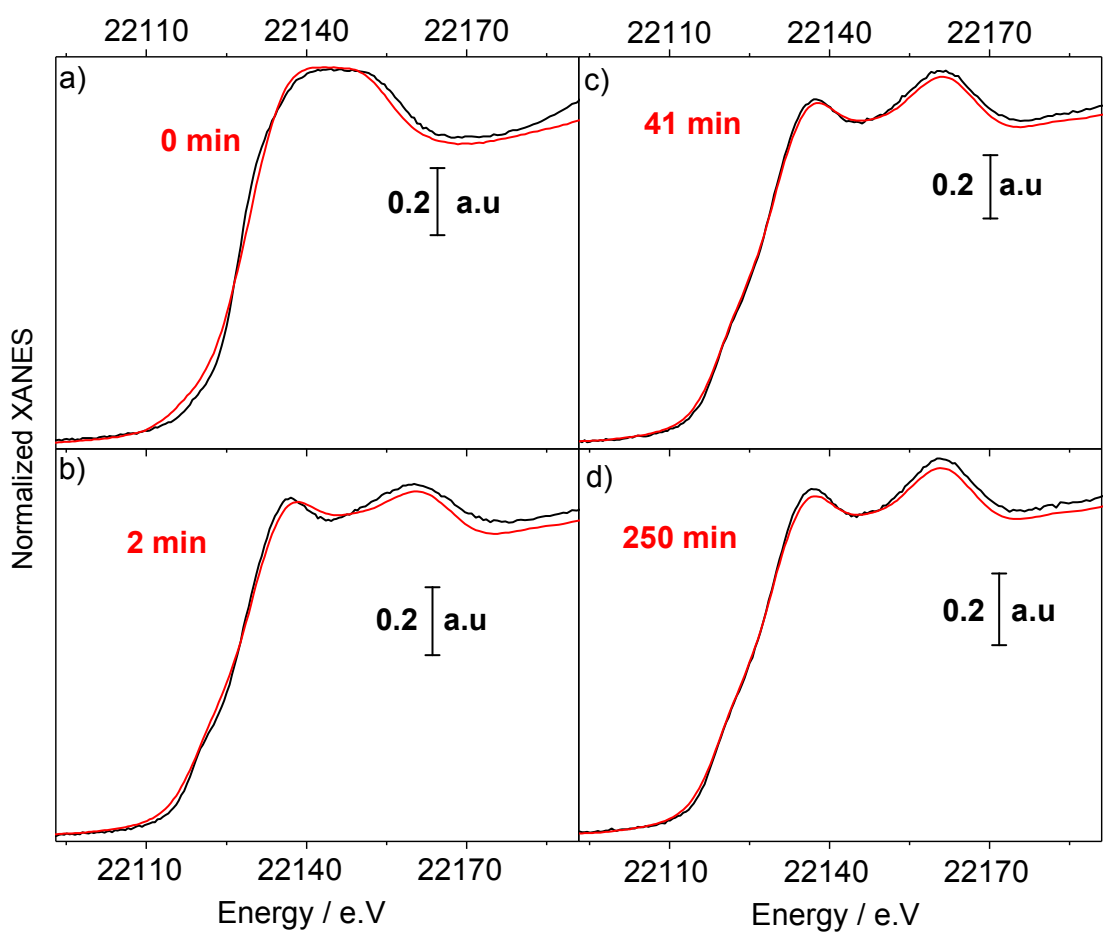

Figure 5 Linear combination analysis fits (red lines) of selected XANES spectra (black lines) recorded at the $\mathrm{Ru} \mathrm{K}$-edge during selective $\mathrm{CO}$ methanation on the $\mathrm{Ru} / \mathrm{TiO}_{2}$ catalyst at $190^{\circ} \mathrm{C}$. a) 0 min corresponds to the catalyst in $\mathrm{N}_{2}$ after calcination at $150^{\circ} \mathrm{C}, \mathrm{b}-\mathrm{d}$ ) during $\mathrm{CO}$ methanation in ID-ref 6000 after 2 min (b), $41 \mathrm{~min}(\mathrm{c})$ and $250 \mathrm{~min}(\mathrm{~d})$ on stream. 
(4 $\pm 1 \%)$. Upon switching to the reaction gas, the XANES spectrum recorded after 2 min $(2-7$ min) showed that the strong white line, which is characteristic for the excitation of $\mathrm{Ru}(1 \mathrm{~s})$ electrons into unoccupied d-states and thus directly proportional to the oxidation state of $\mathrm{Ru}$, has decreased to less than $25 \%$ of its original intensity (see Fig. 6). On a quantitative scale, the LCA indicates a decay of the contribution of $\mathrm{RuO}_{2}$ in the sample from 0.96 (after calcination, $0 \mathrm{~min}$ ) to 0.25 after $2-7 \mathrm{~min}$ on stream.

After 41 min on stream, the contribution of oxidized $\mathrm{Ru}$ in the spectra $\left(\mathrm{RuO}_{2}\right)$ decreased to 0.06 (i.e., metallic $\mathrm{Ru}=0.94$ ). Also after longer reaction times the contribution of $\mathrm{RuO}_{2}$ to the XANES spectra remained stable at $\leq 0.05$ (see Table S1, Supporting Information). The small contribution of oxidic $\mathrm{Ru}$ may result from the interaction of the metal $\mathrm{Ru}$ NPs with lattice oxygen of $\mathrm{TiO}_{2}$ at the contact area. ${ }^{45}$ Hence, the fraction of oxidic $\mathrm{Ru}$ species decreases rapidly during time on stream, reaching a steady-state situation with a contribution of metallic $\mathrm{Ru}$ of $\geq 0.95$ after at most $50 \mathrm{~min}$. This is significantly shorter than the time required for reaching the maximum activity under identical reaction conditions (Fig. 1b), it fits better to

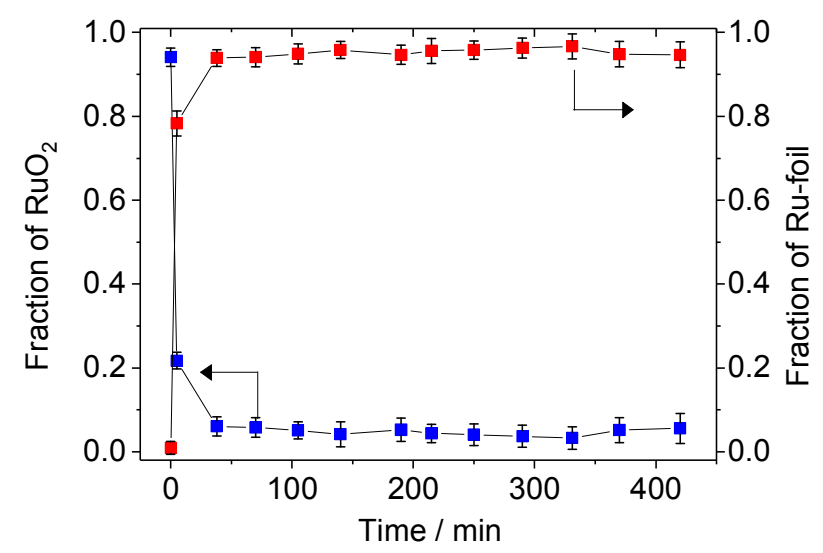

Figure 6 Time evolution of the contributions from oxidized and reduced Ru species to the $\mathrm{Ru}$ K-edge XANES spectrum during the selective $\mathrm{CO}$ methanation on the $\mathrm{Ru} / \mathrm{TiO}_{2}-1$ catalyst, as obtained from a linear combination analysis of the XANES spectra using $\mathrm{RuO}_{2}$ and a $\mathrm{Ru}$ foil as references. 
the time required to reach the maximum $\mathrm{CO}_{\mathrm{ad}}$ coverages (see Fig. 4). Therefore, the reaction is dominated by metallic Ru NPs. We expect that the initial reduction of the catalyst will result in a significant increase in $\mathrm{CO}$ methanation activity in the first few minutes. Even after this reduction process, however, the activity increases, though this increase becomes rather slow after $50-60 \mathrm{~min}$. Hence, there must be another process contributing to the catalyst activation in this period, most likely structural modification of the Ru nanoparticles. Finally, the data clealy demonstrate that the deactivation of the catalyst cannot be related to a reduction or oxidation of the Ru NP surface.

These findings were supported by the results of ex situ XPS measurements, performed after reaction for 10 and $1000 \mathrm{~min}$ in ID-ref 6000 reformate gas at $190^{\circ} \mathrm{C}$ (spectra see Fig. S4a and Table S2, Supporting Information). Here we have to keep in mind that these measurements require transfer of the $\mathrm{Ru} \mathrm{NP}$ catalyst through air, which is likely to cause some surface oxidation. Comparing the binding energy $(\mathrm{BE})$ of the $\mathrm{Ru}\left(3 \mathrm{~d}_{5 / 2}\right)$ state of a catalyst operated for $1000 \mathrm{~min}$ with that after reaction for $10 \mathrm{~min}$, we find a down-shift of the BE by $0.8 \mathrm{eV}$, from 280.1 to $279.3 \mathrm{eV}$. For comparison, reference values for surface oxidized Ru and for metallic $\mathrm{Ru}$ are 280.3 and $279.2 \mathrm{eV} .{ }^{46}$ Hence, these spectra also indicate that the Ru NPs are reduced during reaction, in good agreement with the results of the operando XANES measurements.

The BEs of the $\mathrm{Ti}\left(2 \mathrm{p}_{3 / 2}\right)$ signals of the different $\mathrm{Ru} / \mathrm{TiO}_{2}$ catalysts are located in the range from $458.0 \mathrm{eV}$ and $458.6 \mathrm{eV}$, which is typical for $\mathrm{Ti}^{4+} \cdot{ }^{47 ; 48}$ For all catalysts, we found a slight down-shift in the $\mathrm{BE}$ of the $\mathrm{Ti}\left(2 \mathrm{p}_{3 / 2}\right)$ state by around $0.3 \mathrm{eV}$ during the reaction, e.g., from 458.5 (after $10 \mathrm{~min}$ ) to $458.2 \mathrm{eV}$ (after $1000 \mathrm{~min}$ ) for the $\mathrm{Ru} / \mathrm{TiO}_{2}-1$ catalyst (see Fig. S4a and Table S2, Supporting Information). Apparently, the reaction leads to a slight reduction of the $\mathrm{TiO}_{2}$ support, which often is accompanied by a partial overgrowth of the metal NPs by a thin $\mathrm{TiO}_{\mathrm{x}}(\mathrm{x}<2)$ layer, which would reduce the number of accessible Ru sites. ${ }^{49-52}$ 


\subsubsection{Reaction induced structural changes of $\mathrm{Ru} / \mathrm{TiO}_{2}$ catalysts}

$\mathrm{TiO}_{2}$ structure: We first evaluated XRD measurements to see whether there is a change in the $\mathrm{TiO}_{2}$ crystallite size or phase composition (ratio anatase: rutile) during reaction, which could be a reason for the observed deactivation. Comparing the size of the $\mathrm{TiO}_{2}$ crystallites in the $\mathrm{Ru} / \mathrm{TiO}_{2}-1$ catalyst before and after 1000 min reaction indicated negligible change of the crystallite size (see Table S3 and Fig. S5, Supporting Information). Before reaction, the catalyst showed strong reflections at $25.3^{\circ}$, and $48.1^{\circ}$, which are related to the (101) and (200) planes of anatase ${ }^{53-55}$ and reflections at $27.4^{\circ}, 36^{\circ}$, and $55^{\circ}$, which are assigned to the (110), (101), and (211) planes of rutile. After 1000 min on stream the diffraction pattern did not change much. Quantitative evaluation of the anatase : rutile intensity ratio, using the reflections at $2 \theta=25.373^{\circ}$ (anatase) and $27.52^{\circ}$ (rutile), yielded a constant ratio before and after $1000 \mathrm{~min}$ on stream (see Table S3, Supporting Information). Hence, a structural modification of the support can be excluded as a potential reason for the observed deactivation of the catalyst.

Ru dispersion / particle size and shape: Changes in the average $\mathrm{Ru}$ particle size /dispersion as well as in the particle shape during reaction were followed by ex situ (HR-TEM / XPS) and by time resolved operando EXAFS measurements during reaction in ID-ref 6000 reformate.

First we calculated the change in the atomic ratio of $\mathrm{Ru}: \mathrm{Ti}$ in the surface of the $\mathrm{Ru} / \mathrm{TiO}_{2}-1$ catalyst from the intensities of the $\mathrm{Ru}\left(3 \mathrm{~d}_{5 / 2}\right)$ and Ti $\left(2 \mathrm{p}_{3 / 2}\right)$ peaks in the XPS data discussed in the previous section, after correction by the atomic sensitivity factors (see Fig. S6, Supporting Information). ${ }^{46}$ Comparing the ratio after $10 \mathrm{~min}$ to that after reaction for 1000 min indicated a significant decrease by a factor of about 1.9 (Table S2 and Fig. S6, Supporting Information). Obviously, the concentration of surface $\mathrm{Ru}$ decreases during reaction. Considering the constant overall concentrations in the catalyst, such behavior can result either from $\mathrm{Ru}$ particle size growth or from an overgrowth of the metal particles by $\mathrm{TiO}_{\mathrm{x}}$. 
Using HR-TEM imaging, the particle size distribution of the $\mathrm{Ru}$ NPs of $\mathrm{Ru} / \mathrm{TiO}_{2}-1$ catalyst was measured after reaction in ID-ref 6000 reformate gas for 10, 590 and 1000 min, respectively. The resulting data indicate a rather slow, gradual increase of the Ru particle size with increasing reaction time, from $1.1 \mathrm{~nm}\left(\mathrm{D}_{\mathrm{Ru}}=88.5 \%\right)$ after $10 \min$ to $1.3 \mathrm{~nm}\left(\mathrm{D}_{\mathrm{Ru}}=\right.$ $82.5 \%)$ and $1.6 \mathrm{~nm}\left(\mathrm{D}_{\mathrm{Ru}}=69.0 \%\right)$ after reaction in ID-ref 6000 for 590 and $1000 \mathrm{~min}$, respectively (see Fig. 7).

To gain more information on the particle shape, we determined the ratio of the smaller diameter (width) vs. the longer diameter (length) for each particle and plotted the frequency of different particle diameter ratios (Insets in Figs. 7a, b, c). Looking at a flat, disk-like particle from the side one would obtain a rather low value for the diameter ratio, whereas in a top view this would yield a ratio of 1 . For a spherical particle, in contrast, one would always obtain a ratio of 1 , independent of the angle of view. While a quantitative evaluation of the particle shape from a statistical analysis of the distributions is beyond the present data and also beyond the scope of the present data, the plots nevertheless provide valuable qualitative information. Both after 590 and $1000 \mathrm{~min}$ on stream the data reveal a rather narrow distribution, ranging from a diameter ratio of about 0.5 to 1.0 with a shape that resembles a Gauss distribution and a maximum around 0.8. For the fresh particles, after 10 min initial reaction, the center of mass is also at about 0.8 , but in this case the distribution has a different shape, with significantly higher frequencies at lower diameter ratios, down to 0.3 , and also much higher frequencies at 0.9 and in particular at 1.0. Qualitatively, this means that there was not only a measurable change in particle size in the later phases of the reaction, between 590 and $1000 \mathrm{~min}$, but there is also a significant change in particle shape in the initial phase, with flat particles significantly more abundant initially than in the later phases of the reaction, while in later stages hemispherical particles seem to dominate.

The HR-TEM based results can be compared with the Ru-Ru coordination numbers (CN) 

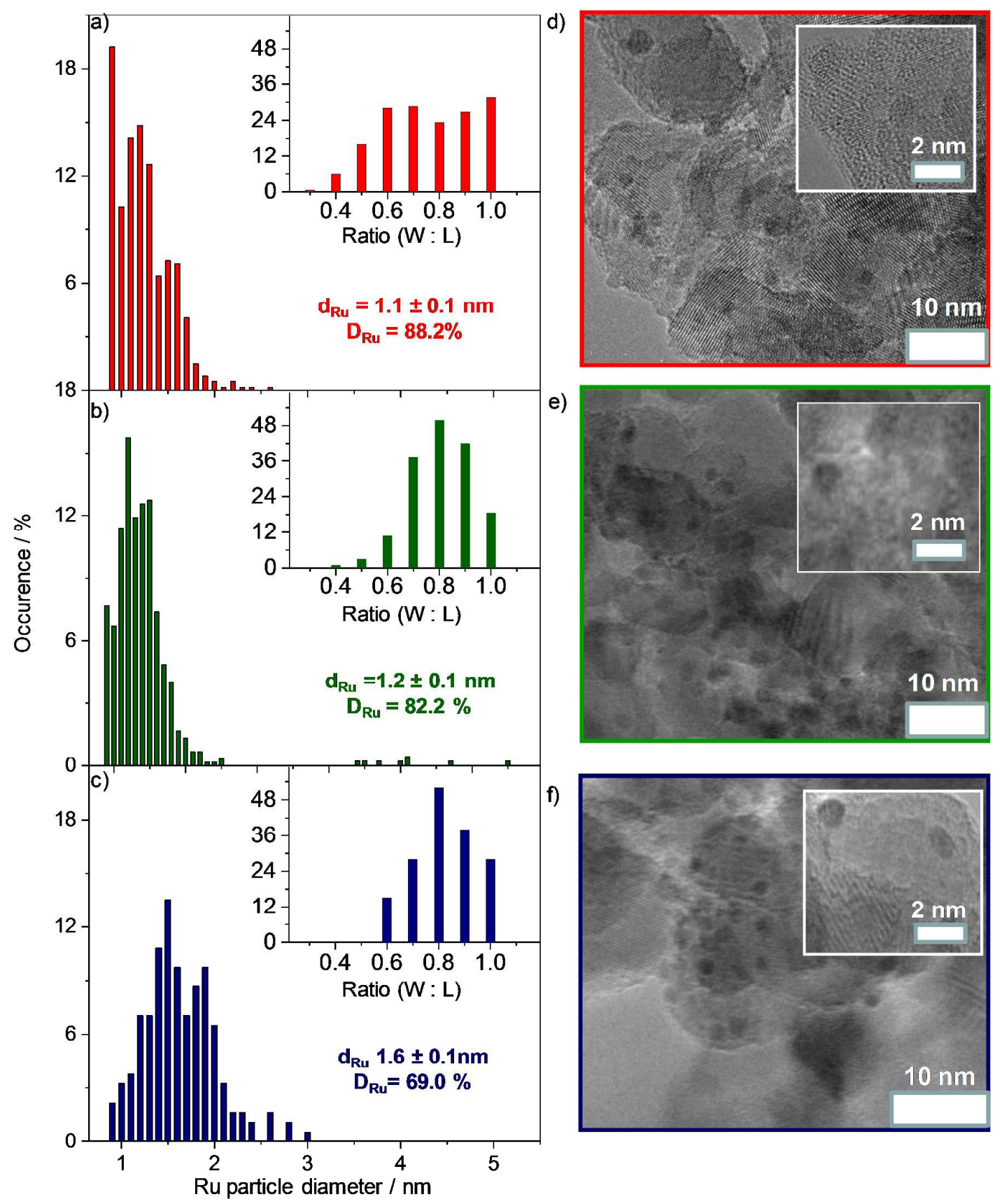

Figure 7 High resolution TEM micrographs of the $\mathrm{Ru} / \mathrm{TiO}_{2}-1$ catalyst and the corresponding $\mathrm{Ru}$ particle size distributions after reaction in ID-ref 6000 for 10 $\min (\mathrm{a}, \mathrm{d}), 590 \mathrm{~min}(\mathrm{~b}, \mathrm{e})$ and for $1000 \mathrm{~min}$ (c, f). Insets in layers (a,b,c) show distribution of width-to-length ratios in Ru nanoparticles. 
Figure 8 Fourier transformed EXAFS data collected at the Ru K-edge during reaction on the $\mathrm{Ru} / \mathrm{TiO}_{2}-1$ catalyst in ID-ref 6000 at different reaction times (data acquisition started after a) $7 \mathrm{~min}$, b) $47 \mathrm{~min}$, c) $379 \mathrm{~min}$, d) $524 \mathrm{~min}$ and e) $595 \mathrm{~min}$ ).

extracted from the EXAFS data at the Ru K-edge. The first EXAFS spectrum was recorded starting 7 min after switching the reaction gas mixture to the cell, and measuring for $30 \mathrm{~min}$.

Fourier transforms of EXAFS spectra recorded after different reaction times are presented in Fig. 8 (a-e), while the corresponding EXAFS data (fit parameters and the $\mathrm{k}^{3}$ weighted Chi 
functions) are presented as supplementary data (Table S4 and Fig. S7, Supporting Information). The EXAFS data were fitted with a Ru-Ru backscatterer. A contribution from a $\mathrm{Ru}-\mathrm{O}$ shell was not detected, although the LCA indicated the presence of an oxidized fraction of 0.217 in the XANES spectrum taken after 2 min on stream (measurement from $2-7$ min) (Table S1, Supporting information). Here we should keep in mind that the data acquisition for an EXAFS spectrum is $30 \mathrm{~min}$, while the XANES region takes only $5 \mathrm{~min}$. Hence, we can assume that the remaining fraction of oxidic $\mathrm{Ru}$ decreases to almost the steady-state value of 0.04 in the time from $7-37 \mathrm{~min}$. The EXAFS result further corroborates the findings derived from the XANES data, which indicated that the oxidation state of $\mathrm{Ru}$ (metalic $\mathrm{Ru}$ ) is about constant after 40 min on stream.

The CN values for Ru NPs extracted from EXAFS data were found to increase steadily during reaction on-stream, first rather quickly from $4.5 \pm 0.6$ at $7-37$ min to $6.2 \pm 0.5$ after $121-151$ min and then slower to $7.5 \pm 0.5$ after 595 - 625 min. Obviously, the dispersion of the Ru NPs decreases during reaction. Qualitatively, this trend is in good agreement with those derived from the TEM and XPS measurements, while on a quantitative scale this is different. For instance, the TEM based mean particle size increases only rather little in the first 590 min, and more over longer times, up to $1000 \mathrm{~min}$. The $\mathrm{CN}$ values, in contrast, exhibit the most pronounced changes in the initial phase, up to $120 \mathrm{~min}$, while later on the growth is slower. These discrepancies can at least partly be resolved when considering also the pronounced changes in particle shape from $10 \mathrm{~min}$ to $590 \mathrm{~min}$. As discussed above, the data indicate a much higher fraction of flatter particles in the beginning, after 10 min on stream, than in the later stages. Considering that flat particles have lower $\mathrm{CN}$ values than hemispherical or even spherical particles, where the exact amount depends on the aspect ratio, the change in particle shape could a least partly account for the pronounced initial changes in the $\mathrm{CN}$ based particle size. The same effect explains also at least partly the distinct discrepancy between the initial 
$\mathrm{CN}$ based and TEM based particle sizes on an absolute scale. After 590 min the Ru particle sizes obtained from $\mathrm{CN}_{\mathrm{Ru}-\mathrm{Ru}}$ and from HR-TEM measurements are about equal, which is $1.1 \pm$ $0.3 \mathrm{~nm}$ (based on a hemi-spherical particle shape ${ }^{, 13}$ ) and $1.3 \pm 0.1 \mathrm{~nm}$, respectively. In total, we conclude that there is a significant change in Ru particle shape in the first about 120 min of the reaction.

\subsubsection{Ru particle size / particle shape effects}

Here we will discuss correlations between the changes in activity and selectivity during reaction of the $\mathrm{Ru} / \mathrm{TiO}_{2}-1$ catalyst in ID-ref 6000 and particle size related data, including also the intensity of the $\mathrm{CO}_{\mathrm{ad}}$ related band, which we assume can be considered as a measure of the $\mathrm{Ru}$ surface area available for the reaction. These data and their variation with time are summarized in Fig. 9.

The $\mathrm{Ru}$ mass normalized $\mathrm{CO}$ methanation rate (data from Fig. 1b) is plotted in Fig. 9a, together with the Ru particle size derived from the EXAFS spectra, assuming hemispherical particle size. It is clear from our previous discussion of the particle shape distribution (section 3.3.2) that this assumption is not correct in the initial phase of the reaction (see discussion in the previous section), but it should be correct for longer reaction times, where TEM data indicate a constant particle shape. Based on the combined TEM and EXAFS data we assume that these are about constant after about $120 \mathrm{~min}$, i.e., from the time where the maximum activity is reached. In that case, particle sizes derived from $\mathrm{CN}$ numbers will be reliable from that point on. This assumption will be justified in the coming discussion. For information, we also included the mean particle size derived from TEM imaging (Fig. 9a). The intensity of the band related to on top adsorbed $\mathrm{CO}_{\mathrm{ad}}$ at $2009 \mathrm{~cm}^{-1}$ is plotted in Fig. 9c. In addition to these data, we plotted the dispersion of the Ru NPs and the turnover frequency (TOF values) determined from the Ru mass normalized rates and the dispersion in Fig. 9b. This assumes that the entire accessible surface of the Ru NPs is active for catalyzing the reaction. 
Looking at the time evolution of these quantities, we can distinguish three different time periods, as indicated in Fig. 9: In the first one, covering about the first $30 \mathrm{~min}$, the activity increases rapidly. The $\mathrm{CO}_{\mathrm{ad}}$ band intensity also shows a steep intial increase, mainly for the first $15 \mathrm{~min}$, and then seems to saturate. Finally, also the (EXAFS based) Ru particle size seems to increase. As discussed before, however, the increase in $\mathrm{CN}$ is at least partly due to a change in particle shape rather than in particle size. Accordingly, this apparent increase in particle size has to be taken with caution. The same is true also for the TOF numbers in this phase. This first phase includes also the reduction of the catalyst, resulting in metallic $\mathrm{Ru}$ NPs. With increasing metallic character of the Ru NPs also the adsorption of $\mathrm{CO}_{\mathrm{ad}}$ increases. The correlation between these trends indicates that the metallic NPs are the active catalysts. In the second phase, ranging up to about $120 \mathrm{~min}$, the $\mathrm{Ru}$ mass normalized activity is still increasing, but the increase is less steep and levels off in the second part of this phase. The intensity of the $\mathrm{CO}_{\mathrm{ad}}$ band changes little, and also the apparent (see above) particle size seems to vary little. Most simply, the trends in this phase can be explained by assuming that the shape modification of the Ru NPs has largely occurred in the first phase, but was not fully completed, while reduction was finished in the first phase.

Finally, the third phase, starting at $120 \mathrm{~min}$, can be considered as the deactivation phase. The ( $\mathrm{Ru}$ mass based) activity of the catalyst decreases continuously, loosing about $25 \%$ during that time. At the same time the Ru particle size increases slowly, from about $0.8 \mathrm{~nm}$ (EXAFS: $0.8 \mathrm{~nm}$, TEM: $1.1 \mathrm{~nm}$ ) to about $1.2 \mathrm{~nm}$ (EXAFS: 1.2, TEM: 1.2$)$ at about $600 \mathrm{~min}$ on stream. TEM data indicate that this increase in particle size continues also at later stages, reaching 1.6 $\mathrm{nm}$ after $1000 \mathrm{~min}$. The more or less continuous increase in particle size (see dashed line) together with the decrease in $\mathrm{Ru}$ mass normalized activity result in a slow increase of the inherent activity of the Ru NPs, indicated by the TOF numbers. A similar increase of the intrinsic activity with increasing Ru particle size was already reported previously for $\mathrm{CO}$ 


\section{9}

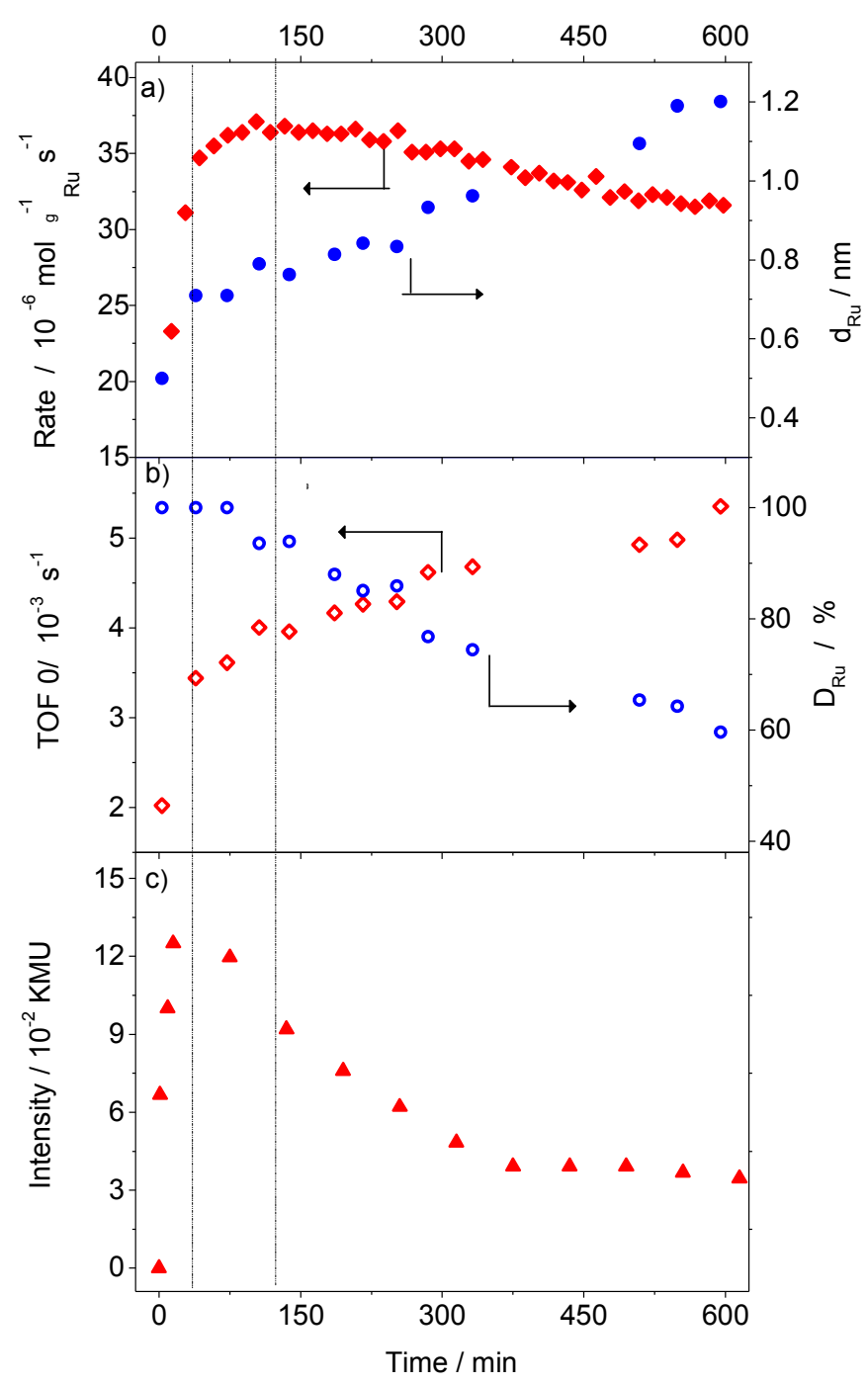

Figure 9 Time evolution of a) the Ru particle size (•), the CO methanation rate (data from Fig. $1 \mathrm{~b}, \diamond)$, b) $\mathrm{Ru}$ dispersion $(\odot)$, turnover frequency $(\diamond)$, and c) on top $\mathrm{CO}_{\mathrm{ad}}$ intensity (data from Fig. 4b, $\mathbf{\Delta}$ : band $2009 \mathrm{~cm}^{-1}$ ) during CO methanation in a IDref 6000 gas mixture. The inset in c) shows the evolution of KMU intensity in the first $10 \mathrm{~min}$. Dashed lines indicate the two activation phases and the deactivation phase (>120 min).

hydrogenation (methanation and Fischer-Tropsch synthesis) on different Ru catalysts. ${ }^{6 ; 9 ; 16 ; 56 ; 57}$ On a microscopic scale this was attributed by several groups to an increasing fraction of surface sites on smooth terraces, indicating that these act as active sites. ${ }^{56 ; 58 ; 59}$ On the other hand, Marini et al. concluded for the $\mathrm{CO}$ methanation on a $\mathrm{Ru} / \mathrm{SiO}_{2}$ catalyst with mass 
selected Ru nanoparticles (particle sizes between 3.7 and $13.5 \mathrm{~nm}$ ) that terraces were more or less inactive, and that steps were the origin of all activity. ${ }^{60}$ Similar conclusions were derived also for reaction on $\mathrm{Ru}$ single crystal surfaces. ${ }^{61}$ The apparent discrepancy with the present observations may be related to the very small particle sizes in the present study, where other particle size related effects, such as size dependent changes in the electronic properties, may also play a role. Alternatively, this may also be related to metal support interactions, which had been demonstrated for $\mathrm{Ru}$ on the reducible $\mathrm{TiO}_{2}$ support, ${ }^{11}$ while it should be absent for $\mathrm{Ru} / \mathrm{SiO}_{2}$ or $\mathrm{Ru}$ single crystal surfaces.

The change of selectivity is another aspect of these structural changes of the Ru NPs. Using the reaction in SR-100 as example, where site blocking by $\mathrm{CO}_{\mathrm{ad}}$ is not dominating the reaction, the selectivity of the $\mathrm{Ru} / \mathrm{TiO}_{2}-1$ catalyst for $\mathrm{CO}$ methanation decays from initially $100 \%$ to $88 \%$ after 1000 min (see Fig. 2). Assuming that the trend of a slow, but continuous particle growth is valid also under these reaction conditions, we obtain a decay in selectivity with increasing $\mathrm{Ru}$ particle size, where the initial mean particle size of $1.1 \mathrm{~nm}$ was sufficiently low to obtain $100 \%$ selectivity. This behavior closely resembles previous findings for $\mathrm{Ru}$ /zeolite and $\mathrm{Ru} / \mathrm{Al}_{2} \mathrm{O}_{3}$ catalysts, which established a clear correlation between the inherent selectivity for $\mathrm{CO}$ methanation and the average Ru particle size, ${ }^{6 ; 9 ; 23}$ and similar particle size effects were reported also for other Ru catalysts, ${ }^{15 ; 16}$. The variation of Ru particle size of $\mathrm{Ru} /$ zeolite, $\mathrm{Ru} / \mathrm{Al}_{2} \mathrm{O}_{3}$ and $\mathrm{Ru} / \mathrm{TiO}_{2}$ catalysts (e.g., by changing the $\mathrm{Ru}$ loading, ${ }^{6}$ the calcination temperature, ${ }^{9}$ the support surface area ${ }^{12}$ or the water content ${ }^{13}$ ) resulted in significant changes of the CO selectivity under reaction conditions identical to those used in the present study. These results were explained by a reaction model based on the BronstedEvans-Polani principle, ${ }^{62}$ where increasing $\mathrm{Ru}$ particles seemed to stabilize $\mathrm{CO}_{\mathrm{ad}}$ and thus stabilize the finale state for $\mathrm{CO}_{2}$ dissociation. According to the BEP model this stabilization reduces the barrier for $\mathrm{CO}_{2}$ dissociation. ${ }^{6 ; 9}$ This trend can also explain the increasing activity 
for $\mathrm{CO}_{2}$ methanation and thus the loss of selectivity for $\mathrm{CO}$ methanation of this $\mathrm{Ru} / \mathrm{TiO}_{2}$ catalyst during time on stream.

\subsection{Impact of the support surface area on the deactivation behavior of the $\mathrm{Ru} / \mathrm{TiO}_{2}$ catalysts}

To identify effects of the catalyst surface area on the activation / deactivation behavior we tested also 3 other catalysts which were based on $\mathrm{TiO}_{2}$ supports with different surface areas (see Table 1). We had demonstrated earlier that the support surface area sensitively affects the catalytic activity of these catalysts by modifying the $\mathrm{Ru}-\mathrm{TiO}_{2}$ metal - support interactions. ${ }^{10 ; 12}$ Kinetic measurements on the different $\mathrm{Ru} / \mathrm{TiO}_{2}$ catalysts both in the SR-ref 6000 (left panels, Fig. 10a-c) and in ID-ref 6000 reformates (right panels, Fig. 10d-f) exhibited a deactivation behavior which closely resembles that observed for the $\mathrm{Ru} / \mathrm{TiO}_{2}-1$ catalyst with two differences. First, the initial activation period increases with increasing support surface area (see Table 3). Second, the relative deactivation, calculated after $1000 \mathrm{~min}$ on stream, decreased with increasing support surface area, from $44 \%$ on the $\mathrm{Ru} / \mathrm{TiO}_{2}-2$ catalysts $\left(20 \mathrm{~m}^{2} \mathrm{~g}^{-}\right.$ $\left.{ }^{1}\right)$ to $18 \%$ for the $\mathrm{Ru} / \mathrm{TiO}_{2}-4$ catalyst $\left(235 \mathrm{~m}^{2} \mathrm{~g}^{-1}\right)$.

For the $\mathrm{Ru} / \mathrm{TiO}_{2}-2$ catalyst, which showed the most pronounced activation / deactivation, we also explored changes in the Ru particle size after operating the catalyst for 10 min and 1000 min and compared these with the changes for the $\mathrm{Ru} / \mathrm{TiO}_{2}-1$ catalyst discussed before (section 3.3). For the $\mathrm{Ru} / \mathrm{TiO}_{2}-2$ catalyst, HR-TEM measurements (see Fig. 11) indicated a more pronounced increase of the mean $\mathrm{Ru}$ particle size from $1.2 \mathrm{~nm}\left(\mathrm{D}_{\mathrm{Ru}}=88.5\right.$ from HR-TEM $)$ after $10 \mathrm{~min}$ reaction to $2.3 \mathrm{~nm}\left(\mathrm{D}_{\mathrm{Ru}}=48.0 \%\right.$ - HR-TEM) after reaction for $1000 \mathrm{~min}$. Comparison of micrographs taken after 10 min indicated a homogeneous distribution of $\mathrm{Ru}$ NPs with a rather high density of particles in the beginning of reaction, which after $1000 \mathrm{~min}$ had decreased significantly. It should be noted that in a previous study on these catalysts we 

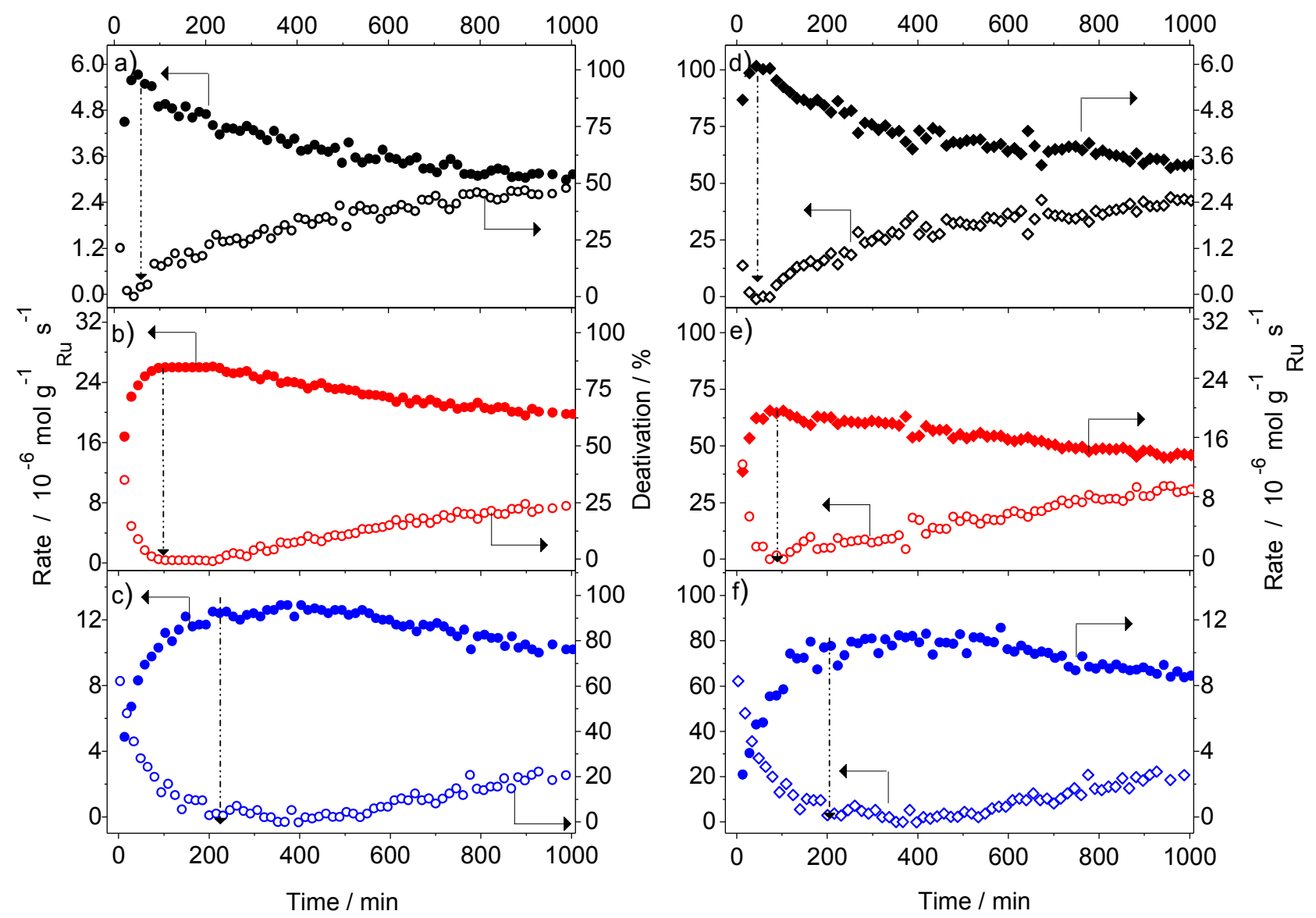

Figure 10 Temporal evolution of the $\mathrm{CO}$ methanation rate (filled symbols) and the corresponding deactivation (open symbols) in SR-ref 6000 (left panels) and in IDref 6000 (right panels) on $\mathrm{Ru} / \mathrm{TiO}_{2}$ catalysts with different surface areas (reaction temperature $190^{\circ} \mathrm{C}$ ): (a,d) $\mathrm{Ru} / \mathrm{TiO}_{2}-2$, (b,e) $\mathrm{Ru} / \mathrm{TiO}_{2}-3$, (c,f) $\mathrm{Ru} / \mathrm{TiO}_{2}-4$.

had found that the metal-support interactions were much weaker on the $\mathrm{Ru} / \mathrm{TiO}_{2}-2$ than on the $\mathrm{Ru} / \mathrm{TiO}_{2}-1$ catalyst, ${ }^{11}$ which might explain the increased tendency for Ru particle growth in the $\mathrm{Ru} / \mathrm{TiO}_{2}-2$ catalyst (Fig. S8, Supporting Information). Similar to the $\mathrm{Ru} / \mathrm{TiO}_{2}-1$ catalyst we evaluated the changes in the Ru NPs shapes based on the ratio of the short (W) and long diameter (L). Also in this case, the fraction of flat particles (ratios $<0.6$ ) on $\mathrm{Ru} / \mathrm{TiO}_{2}-2$ after 10 min was found to decrease during the reaction (1000 min on stream, Fig.11 - insets). In this case, however, the center of mass after $1000 \mathrm{~min}$ is slightly higher (around 0.85) compared to $\mathrm{Ru} / \mathrm{TiO}_{2}-1(0.8)$. 

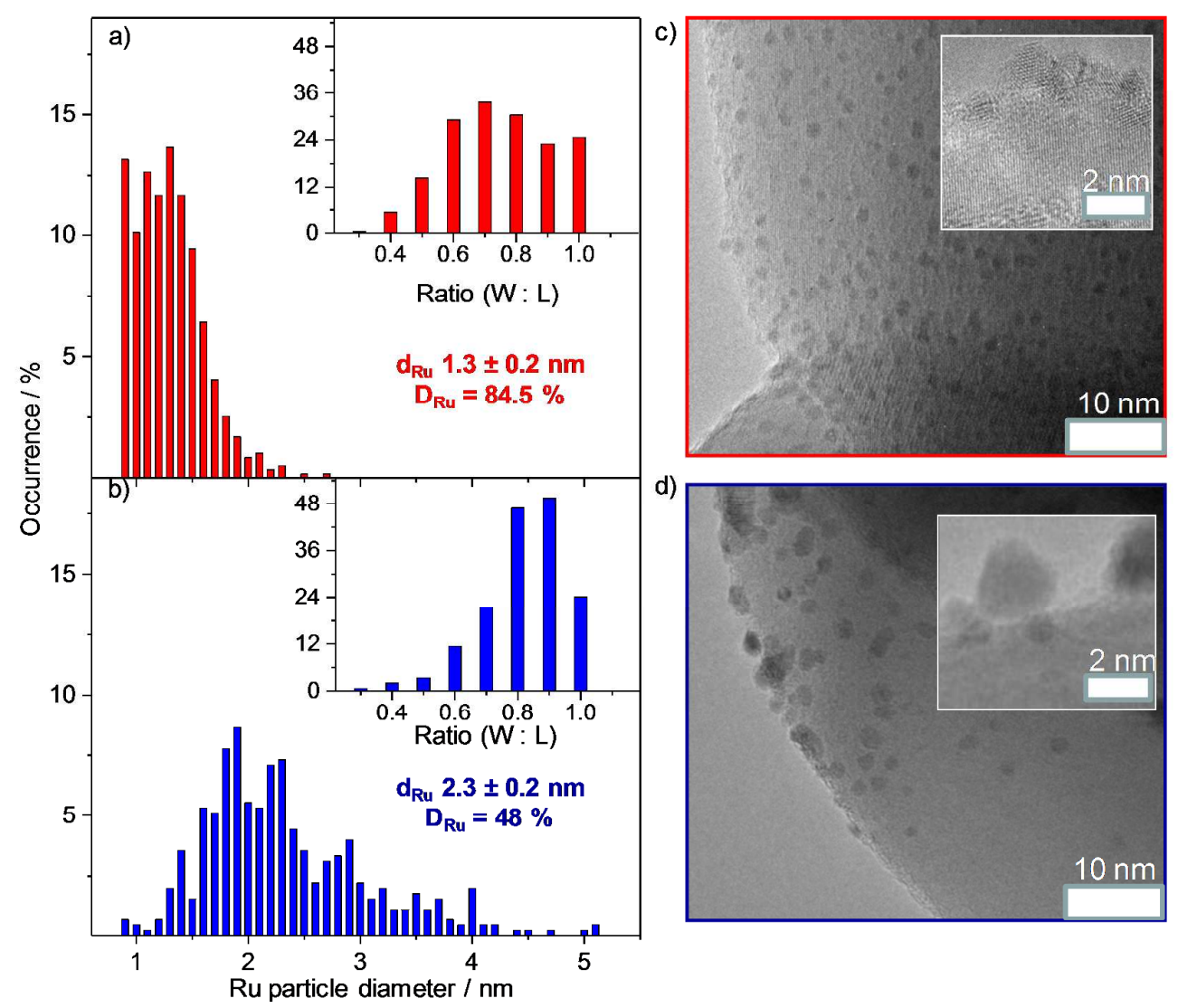

Figure 11 High resolution TEM micrographs of the $\mathrm{Ru} / \mathrm{TiO}_{2}-2$ catalyst and the corresponding $\mathrm{Ru}$ particle size (left panel) and particle shape (left panel, insets) distributions after reaction in ID-ref 6000 for $10 \mathrm{~min}(\mathrm{a}, \mathrm{c})$ and for $1000 \mathrm{~min}(\mathrm{~b}$, d).

Similar to the $\mathrm{Ru} / \mathrm{TiO}_{2}-1$ catalyst, we also tested the deactivation behavior at low $\mathrm{CO}$ concentrations, in SR-ref 100 reformate, where $\mathrm{Ru}$ site blocking by adsorbed $\mathrm{CO}$ is not important. The magnitude of the deactivation was found to increase with decreasing support surface area, similar to the trend for reaction at higher CO concentrations (SR-ref 6000 and ID-ref 6000). Also the CO selectivity, or more specifically, the decay of the selectivity with time on stream, varied with the support surface area (see Table 4), with a more pronounced decay for lower surface areas. 
All catalysts were essentially fully selective for $\mathrm{CO}$ methanation in the beginning of the reaction, but the selectivity decayed with different amounts during time on stream (Fig. S9, Supporting Information). While for the high surface area catalysts, $\mathrm{Ru} / \mathrm{TiO}_{2}-4$ and $\mathrm{Ru} / \mathrm{TiO}_{2}-1$, the decay was negligible or rather low, it became significant or even very pronounced for the lower surface area catalysts $\mathrm{Ru} / \mathrm{TiO}_{2}-3$ and $\mathrm{Ru} / \mathrm{TiO}_{2}-2$ (see Table 4). The initial high selectivity is mainly related to the presence of small $\mathrm{Ru}$ NPs $\left(1.1 \mathrm{~nm}\right.$ on $\mathrm{Ru} / \mathrm{TiO}_{2}-1$ and 1.3 $\mathrm{nm} \mathrm{Ru} / \mathrm{TiO}_{2}-2$, assuming hemispherical NPs (see discussion in 3.3)). The difference in the final selectivity also correlated with the $\mathrm{Ru}$ particle $\mathrm{Ru}$ size. $\mathrm{Ru} / \mathrm{TiO}_{2}-1$ with the higher selectivity ( $88 \%$ ) has significantly smaller Ru NPs (TEM: $\left.d_{R u}=1.6 \mathrm{~nm}\right)$ compared to the

Table 4: Initial and final (after 1000 min on stream) rates for $\mathrm{CO}$ methanation and $\mathrm{CH}_{4}$ formation and the corresponding selectivities in SR-ref 100 reformate gas (reaction temperature $\left.190^{\circ} \mathrm{C}\right)$.

\begin{tabular}{|c|c|c|c|c|}
\hline \multirow{2}{*}{ Catalyst } & \multicolumn{2}{|c|}{ Reaction rate $* 10^{-6} / \mathrm{mol} \mathrm{g}_{\mathrm{Ru}}{ }^{-1} \mathrm{~s}^{-1}$} & \multicolumn{2}{c|}{ Selectivity / \% } \\
\cline { 2 - 5 } & Initial $\left(\mathrm{CO} / \mathrm{CH}_{4}\right)$ & Final $\left(\mathrm{CO} / \mathrm{CH}_{4}\right)$ & Initial & Final \\
\hline $\mathrm{Ru} / \mathrm{TiO}_{2}-1$ & $65.6 / 65.6$ & $34.8 / 39.1$ & 100 & 89 \\
\hline $\mathrm{Ru} / \mathrm{TiO}_{2}-2$ & $6.8 / 7.0$ & $2.10 / 3.70$ & 97 & 57 \\
\hline $\mathrm{Ru} / \mathrm{TiO}_{2}-3$ & $34.5 / 33.5$ & $18.5 / 24.6$ & 100 & 75 \\
\hline $\mathrm{Ru} / \mathrm{TiO}_{2}-4$ & $31.6 / 31.5$ & $26.5 / 27.1$ & 100 & 97 \\
\hline
\end{tabular}

* Selectivity is the ratio of the $\mathrm{CO}$ methanation rate to the total $\mathrm{CH}_{4}$ formation rate (from $\mathrm{CO}$ and $\mathrm{CO}_{2}$ ).

$\mathrm{Ru} / \mathrm{TiO}_{2}-2$ catalyst $\left(\mathrm{TEM}: \mathrm{d}_{\mathrm{Ru}}=2.3 \mathrm{~nm}\right.$ ) with its much lower selectivity of $57 \%$.

These findings further support our previous proposal that the inherent selectivity of supported $\mathrm{Ru}$ catalysts is sensitively controlled by the Ru particle size. ${ }^{6 ; 9-12 ; 14}$ A high inherent selectivity, in the absence of Ru site blocking by $\mathrm{CO}_{\mathrm{ad}}$, is reached only for very small Ru NPs. ${ }^{6 ; 9}$

Finally, we used both XPS and XRD to characterize reaction induced changes in the surface composition of the $\mathrm{Ru} / \mathrm{TiO}_{2}$ catalysts and in the size and phase composition of the $\mathrm{TiO}_{2}$ support particles for the different catalysts. 
XPS measurements performed after reaction for 10 and $1000 \mathrm{~min}$, respectively, showed a similar trend for all other catalysts as observed for the $\mathrm{Ru} / \mathrm{TiO}_{2}-1$ catalyst, with the $\mathrm{Ru}$ concentration in the catalyst surface decreasing with time on stream (Fig. S5 and Fig. S6, Supporting Information). Comparing the intensities of the $\mathrm{Ru} 3 \mathrm{~d}_{5 / 2}$ and of the Ti $2 \mathrm{p}_{3 / 2}$ peak, the $\mathrm{Ru}$ : Ti atomic ratio of the catalyst with the highest surface area $\left(\mathrm{Ru} / \mathrm{TiO}_{2}-4\right)$ decreased by a factor of 1.6 after reaction for $1000 \mathrm{~min}$, while this decrease was more pronounced for the other three catalysts. Most simply this can be explained by a less significant loss of $\mathrm{Ru}$ dispersion (growth of the Ru NPs) on the latter catalyst. This explanation would also fit with the lower deactivation observed on that catalyst. The Ru (3d) and Ti (2p) binding energies showed similar changes as described before for $\mathrm{Ru} / \mathrm{TiO}_{2}-1$, with both shifting to slightly lower values after reaction for $1000 \mathrm{~min}$ (Table S2, Supporting Information). A decrease of the BEs by $0.3-0.4 \mathrm{eV}$ after 1000 min reaction was observed for all catalysts. Hence, the reduction of the support is not affected much by the surface area. Furthermore, for the $\mathrm{Ru} / \mathrm{TiO}_{2}-2$ catalyst with the lowest surface area, the $\mathrm{Ru}(3 \mathrm{~d}) \mathrm{BE}(279.0 \mathrm{eV} \pm 0.1 \mathrm{eV})$ was measurably lower than that of the other catalysts $(279.3 \pm 0.1 \mathrm{eV})$, which we attribute to a particle size effect, resulting from the significantly bigger $\mathrm{Ru}$ particles on the $\mathrm{Ru} / \mathrm{TiO}_{2}-2$ catalyst compared to the other catalysts.

In principle, one could also determine the accumulation of deposited carbon species from these XPS data. Here it has to be kept in mind, however, that there is a considerable uptake of hydrocarbon species during sample transport through air, which precludes a quantitative evaluation of such data. As expected for such contamination effects, the $\mathrm{C} 1 \mathrm{~s}$ intensity in the spectra in Fig. S4 (Supporting Information) increases with surface area of the catalyst.

XRD analysis of the catalysts after reaction for 10 and 1000 min revealed that differences in size and phase composition of the $\mathrm{TiO}_{2}$ crystallites are insignificant, which further supported our previous conclusion that such changes in the support can essentially be ruled out as 
significant contributions to the deactivation of these catalysts in the $\mathrm{CO}$ methanation reaction under present reaction conditions (see Fig. S5 and Table S3, Supporting Information).

The growth of the small metal nanoparticles during reaction can proceed via different mechanisms, such as Ostwald ripening, or particle coalescence. ${ }^{63 ; 64}$ From the present data it is not possible to identify the exact growth mechanism. Considering the constant metal loading, the increasing spacing between Ru NPs with increasing support surface area is also expected to lower the tendency for Ru particle growth. ${ }^{65}$ Furthermore, we previously demonstrated for the same group of catalysts that the increasing surface area goes along with an increase of metal-support interactions, ${ }^{11}$ which can also effect the tendency for particle growth. ${ }^{63}$ Stronger metal-support interactions due to an increasing tendency for $\mathrm{O}$ vacancy formation with varying support particle size (= varying support surface area) had been detected theoretically for ceria recently. ${ }^{66}$

Finally it should be noted that in previous studies residual $\mathrm{Cl}$ had been reported to affect the selectivity of supported $\mathrm{Ru}$ catalysts for $\mathrm{CO}$ methanation. ${ }^{67 ; 68}$, shifting the onset of $\mathrm{CO}_{2}$ methanation to higher temperatures. This results in a wider temperature range with high selectivities for $\mathrm{CO}$ methanation. Therefore, we quantified the amounts of residual $\mathrm{Cl}$ on the four samples by EDX as well as by XPS measurements, once after calcination and $10 \mathrm{~min}$ reaction and once after additional 1000 min on stream. In the EDX analysis, a bulk sensitive technique, we did not detect any measurable signal for $\mathrm{Cl}$, indicating that the bulk $\mathrm{Cl}$ content is below 0.1 at.\%. XPS analysis, on the other hand, which is sensitive to the topmost few layers of the catalyst only, detected residual $\mathrm{Cl}$ contents in the range 0.4 to 1 at.\% after calcination and 10 min reaction. After another 1000 min reaction, the surface contents were in the range $0.3-0.5$ at.\%. While we cannot rule out that the presence of $\mathrm{Cl}$ surface trace impurities in the fresh samples may contribute to the high selectivity (100\%) observed during the first few minutes of the reaction, this is different for the performance after longer reaction 
times (see Figure S10 - Supporting Information). The trend of increasing selectivity after 1000 min on stream with increasing surface area (which corresponds also to decreasing $\mathrm{Ru}$ particle size) is not correlated with a similar trend in increasing levels of $\mathrm{Cl}$ surface impurities, instead these are low and about similar for all catalysts. Hence, under these conditions this represents a genuine effect of the catalysts, caused by the increasing surface area of the support together with the decreasing particle size and decreasing tendency for particle growth during time on stream.

\subsection{Effect of water on the catalyst deactivation}

Since water is a byproduct of this reaction, we finally studied the impact of water on the activation and deactivaton behavior of the $\mathrm{Ru} / \mathrm{TiO}_{2}-2$ catalyst, which showed the shortest activation period and the highest tendency for deactivation in the absence of water (44\%). We followed the changes in the catalytic activity for $800 \mathrm{~min}$ in SR-ref 6000 in the presence of $15 \%$ water vapor at $190^{\circ} \mathrm{C}$. Water was added by bubbling the dry gas mixture through a water bath at fixed temperature (for more information see ref. ${ }^{13}$ ). We observed an almost similar reaction behavior in the presence of water as in the absence of water (see Fig. 10a). In the presence of water methane formation reached its highest rate of $7.2 \times 10^{-6} \mathrm{~mol} \mathrm{~g}_{\mathrm{Ru}}{ }^{-1} \mathrm{~s}^{-1}$ in $25 \mathrm{~min}$ (see Fig. 12), similar to the time this took in the absence of water. Afterwards, the activity decayed with time on stream at a similar rate as in the absence of water (see Fig. 10a) reaching $3.7 \times 10^{-6} \mathrm{~mol} \mathrm{~g}_{\mathrm{Ru}}{ }^{-1} \mathrm{~s}^{-1}$ after $800 \mathrm{~min}$ on stream, equivalent to a total deactivaton of $47 \%$, which is of similar order of magnitude as in the absence of water (44\%). 


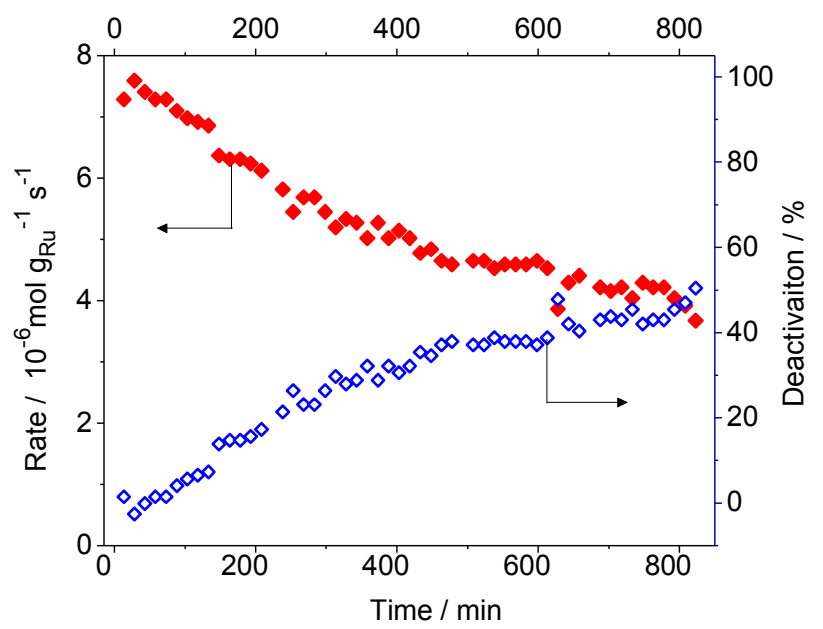

Figure 12 Temporal evolution of the $\mathrm{CO}$ methanation rate $(\diamond)$ and the corresponding deactivation $(\diamond)$ in SR-ref 6000 gas mixture saturated with $15 \%$ water over the $\mathrm{Ru} / \mathrm{TiO}_{2}-2$ catalyst (reaction temperature $190^{\circ} \mathrm{C}$ ) .

In previous studies on $\mathrm{Ru} / \mathrm{Al}_{2} \mathrm{O}_{3}$ and $\mathrm{Ru}$ /zeolite catalysts we had observed that the addition of up to $15 \%$ water vapor to the reaction gas mixture, using an identical feed gas, resulted in a slight decrease in the catalytic activity, both for the initial and final activity for COmethanation, while $\mathrm{CO}_{2}$ methanation was fully suppressed ${ }^{13}$. Using a low-CO reformate (SR-ref 100), the selectivity was below $100 \%$, except for very small Ru NPs. In those cases the selectivity was found to increase, reflecting a decreasing $\mathrm{CO}_{2}$ methanation rate, upon addition of water to the gas mixture. This was explained by the simultaneous decrease of the mean Ru particle size determined by operando EXAFS measurements. ${ }^{10 ; 12 ; 13}$ The selectivity remained at $100 \%$, as expected for the higher CO concentration (see section 3.1).

Based on these observations and earlier findings we can largely exclude the possibility of deactivation due to the formation of water during the reaction.

\section{Summary and main conclusions}

Aiming at a fundamental understanding of the physical origin of the observed activation and deactivation of $\mathrm{Ru} / \mathrm{TiO}_{2}$ catalysts during the selective methanation of $\mathrm{CO}$, we have systemati- 
cally studied this reaction in different reformate gas mixtures by a combination of kinetic measurements, time resolved operando XAS and in situ infrared spectroscopy measurements as well as ex situ characterization by XPS, XRD and TEM. This led to the following main results and conclusions:

i) Fully oxidized $\mathrm{Ru} / \mathrm{TiO}_{2}$ catalysts, obtained after pretreatment in an oxidative atmosphere, show an initial activation phase, followed by a continuous deactivation. This goes along with a rapid reduction of the Ru NPs, whose oxide content decreases by $\sim 90 \%$ in the first $10 \mathrm{~min}$ and reaches a steady-state content of oxidized $\mathrm{Ru}$ species of $<5 \%$ at extended reaction time $\geq 40 \mathrm{~min}$. In addition to this reduction process, which dominates the catalyst activation in the first $30 \mathrm{~min}$, also the shape of the Ru NPs changes distinctly, towards more hemispeherical particles. Based on a combinatiation of EXAFS and TEM data this proceeds up to the observed activity maximum at about $120 \mathrm{~min}$, indicating that this also contribute to the activation, in particular in the second phase of the activation phase, from 30 to $120 \mathrm{~min}$. Neither changes in the oxidation state nor changes in particle shape correlate with the catalyst deactivation, which occurs at later times and on a different time scale.

ii) This activation period gets longer with increasing support surface area, while the rate of the relative deactivation decreases with increasing surface area. The latter is attributed to the slower growth of the Ru particles with increasing support surface area, as indicated from the different increase in Ru particle size between 10 min and 1000 min on stream $\left(\mathrm{Ru} / \mathrm{TiO}_{2}-2\left(\mathrm{SA}=20 \mathrm{~m}^{2} \mathrm{~g}^{-1}\right) \mathrm{d}_{\mathrm{Ru}}: 1.2 \mathrm{~nm} @ 10 \mathrm{~min}\right.$ to $2.3 \mathrm{~nm} @ 1000 \mathrm{~min}$ compared to $\mathrm{Ru} / \mathrm{TiO}_{2}-1\left(\mathrm{SA}=121 \mathrm{~m}^{2} \mathrm{~g}^{-1}\right) \mathrm{d}_{\mathrm{Ru}}: 1.1 \mathrm{~nm} @ 10 \mathrm{~min}$ to $\left.1.6 \mathrm{~nm} @ 1000 \mathrm{~min}\right)$. The slower increase in the size of Ru NPs on larger surface area was attributed previously ${ }^{11}$ to a significant increase in the MSI interaction with increasing surface area, which can presumably be responsible for stabilizing the metal nanoparticles. 
iii) The deactivation, starting after $\sim 120 \mathrm{~min}$ in reformate gases with medium CO content $(0.6 \% \mathrm{CO})$, is mainly attributed to a structural effect, to slow growth of the Ru NPs during time on stream.

iv) During the deactivation phase the TOF based activity increases, while the $\mathrm{Ru}$ mass normalized activity decreases concurrently, which implies that the deactivation is attributed in part to the decrease of the overall number of active sites.

v) All catalysts were $\sim 100 \%$ selective for $\mathrm{CO}$ methanation $\left(0 \% \mathrm{CO}_{2}\right.$ methanation $)$ at the beginning of the reaction both in SR-ref 6000 and in SR-ref 100 gas mixtures, independent of their surface area. In agreement with previous findings for $\mathrm{Ru} /$ zeolite catalysts, ${ }^{6 ; 9 ; 10}$ this is attributed to the high dispersion (small size) of the Ru NPs in the beginning of the reaction. Very small Ru NPs prevail at this stage (0.8 to $1.1 \mathrm{~nm})$, which are stable for a certain period (roughly $100 \mathrm{~min}$ ), and then grow with different rates during the reaction, depending on the surface area of the $\mathrm{TiO}_{2}$ support (faster growth for lower specific surface areas). Since this particle size effect was reported on different catalyst supports, $6 ; 10 ; 11 ; 15 ; 16$ the correlation between Ru particle size and selectivity for CO methanation is considered to be of general validity, independent of the support.

vi) The accumulation of surface formate / bicarbonate species, which form mainly from the interaction of $\mathrm{CO}_{2}$ with the $\mathrm{TiO}_{2}$ support, does not seem to contribute significantly to the long-term deactivation of the catalysts, since it saturates already after $280 \mathrm{~min}$, while deactivation continues over the entire time on stream (1000 min). Furthermore, the buildup of formate / bicarbonate species in the absence of $\mathrm{CO}_{2}$ was at least 20 times less than in the presence of $\mathrm{CO}_{2}$, although the catalyst showed similar deactivation in both cases.

vii) Similarly, deposition of surface carbon or adsorbed $\mathrm{CH}_{\mathrm{x}}$ species is found to be insignificant under present reaction conditions, and can at most be a minor contribution to the observed deactivation. 
viii) The addition of 5\% water in the reaction gas during reaction did not result in any significant changes in the activation or deactivation process of the most strongly deactivating $\mathrm{Ru} / \mathrm{TiO}_{2}-2$ catalyst, indicating that site blocking by adsorption of water or $\mathrm{Ru}$ particle restructuring by interaction with water, where the water may either be present in the feed gas or formed in the reaction, does not play a major role for the (de-)activation processes.

Based on these results the deactivation behavior observed during the selective methanation of $\mathrm{CO}$ at $190^{\circ} \mathrm{C}$ on $\mathrm{Ru} / \mathrm{TiO}_{2}$ catalysts, including losses in activity and inherent selectivity for $\mathrm{CO}$ methanation, is mainly caused by structural effects, by slow growth of the initially very small $\mathrm{Ru}$ NPs. The tendency for particle growth decreases with higher surface area of the $\mathrm{TiO}_{2}$ support, which is ascribed to increasing metal support interactions. In contrast, activation of oxidatively pretreated catalysts is mainly related to reduction of the catalysts, together with changes in the particle shape, from higher fractions of flat particles in the initial phase to hemispherical particles in later stages of the activation phase. Poisoning of active sites by building of carbon containing species can be excluded as possible reason for the catalyst deactivation, and accumulation of these species occurs dominantly on the $\mathrm{TiO}_{2}$ support.

\section{ASSOCIATED CONTENT}

\section{Supporting Information}

The Supporting Information is available free of charge on the ACS Publications website at DOI: $10.1021 /$ acscatal.7b01563.

Kinetic, XANES, EXAFS, XPS and TEM data

\section{AUTHOR INFORMATION}

\section{Corresponding Author:}

E-mail: juergen.behm@uni-ulm.de. 


\section{ORCID}

R. Jürgen Behm: 0000-0002-7565-0628

\section{Permanent Address}

Ali M. Abdel-Mageed: Department of Chemistry, Faculty of Science, Cairo University, Giza 12613, Egypt

\section{Notes}

The authors declare no competing financial interest.

\section{Acknowledgements}

The work at DTU was supported by a research grant (9455) from VILLUM FONDEN. We thank the Elettra synchrotron - XAFS beamline and the beam line scientists Dr. G. Acquilanti and Dr. L. Olivi for the support during the synchroton measurements. We also extend our gratitude to Dr. Thomas Diemant for XPS measurements (Institute of Surface Chemistry and Catalysis - Ulm University) and Dr. J. Biskupek for HR-TEM measurements (Central Facility of Electron Microscopy - Ulm University). 


\section{References}

1. Chen, A.; Miyao, T.; Higashiyama, K.; Yamashita, H.; Watanabe, M., High Catalytic Performance of Ruthenium-Doped Mesoporous Nickel-Aluminum Oxides for Selective CO Methanation, Angew. Chem. Int. Ed. 2010, 49, 9895-9898.

2. Ercolino, G.; Ashraf, M. A.; Specchia, V.; Specchia, S., Performance Evaluation and Comparison of Fuel Processors Integrated with PEM Fuel Cell Based on Steam or Autothermal Reforming and on CO Preferential Oxidation or Selective Methanation, Appl. Energy 2015, 141, 138-153.

3. Takenaka, S.; Shimizu, T.; Otsuka, K., Complete Removal of Carbon Monoxide in Hydrogen-Rich Gas Stream through Methanation over Supported Metal Catalysts, Int. J. Hydrogen Energy 2004, 29, 1065-1073.

4. Panagiotopoulou, P.; Kondarides, D. I.; Verykios, X. E., Selective Methanation of CO over Supported Noble Metal Catalysts: Effects of the Nature of the Metallic Phase on Catalytic Performance, Appl. Catal. A 2008, 344, 45-54.

5. Eckle, S.; Anfang, H.-G.; Behm, R. J., What Drives the Selectivity for CO methanation in the Methanation of $\mathrm{CO}_{2}$-Rich Reformate Gases on Supported Ru Catalysts?, Appl. Catal. A 2011, 391, 325-333.

6. Eckle, S.; Augustin, M.; Anfang, H.-G.; Behm, R. J., Influence of the Catalyst Loading on the Activity and the $\mathrm{CO}$ Selectivity in the Selective Methanation of $\mathrm{CO}$ in $\mathrm{CO}_{2}$ Containing Feed Gases over Ru Supported Catalysts, Catal. Today 2012, 181, 40-51.

7. Tada, S.; Kikuchi, R., Mechanistic Study and Catalyst Development for Selective Carbon Monoxide Methanation, Catal. Sci. Technol. 2015, 5, 3061-3070.

8. Wang H.; Pei, Y.; Qiao, M.; Zong, B., Advances in methanation catalysis, Catalysis (Royal Society of Chemistry - London); 2017; Volume 29, pp.1-28.

9. Abdel-Mageed, A. M.; Eckle, S.; Anfang, H.-G.; Behm, R. J., Selective CO Methanation in $\mathrm{CO}_{2}$-rich $\mathrm{H}_{2}$ Atmospheres over a $\mathrm{Ru} /$ zeolite Catalyst: The Influence of Catalyst Calcination, J. Catal. 2013, 298, 148-160.

10. Abdel-Mageed, A. M.; Eckle, S.; Behm, R. J., High Selectivity of Supported Ru Catalysts in the Selective CO Methanation - Water Makes the Difference, J. Am. Chem. Soc. 2015, 137, 8672-8675.

11. Abdel-Mageed, A. M.; Widmann, D.; Olesen, S. E.; Chorkendorff, I.; Biskupek, J.; Behm, R. J., Selective CO Methanation on $\mathrm{Ru} / \mathrm{TiO}_{2}$ Catalysts: Role and Influence of Metal - Support Interactions, ACS Catal. 2015, 5, 6753-6763.

12. Abdel-Mageed, A. M.; Widmann, D.; Eckle, S.; Behm, R. J., Improved Performance of $\mathrm{Ru} / \gamma-\mathrm{Al}_{2} \mathrm{O}_{3}$ Catalysts in the Selective Methanation of $\mathrm{CO}$ in $\mathrm{CO}_{2}$-Rich Reformate Gases 
upon Transient Exposure to Water Containing Reaction Gas, Chem.Sus.Chem. 2015, 8, 3869-3881.

13. Abdel-Mageed, A. M.; Kucèrová, G.; Abd El-Moemen, A.; Bansmann, J.; Widmann, D.; Behm, R. J., Geometric and Electronic Structure of $\mathrm{Au}$ on $\mathrm{Au} / \mathrm{CeO}_{2}$ Catalysts during the CO Oxidation: Deactivation by Reaction Induced Particle Growth, J. Phys.: Conf. Series 2015, 712, 012044-1

14. Abd El-Moemen, A.; Abdel-Mageed, A. M.; Bansmann, J.; Parlinska-Wojtan, M.; Behm, R. J.; Kucèrová, G., Deactivation of $\mathrm{Au} / \mathrm{CeO}_{2}$ catalysts in the $\mathrm{CO}$ Oxidation Reaction: Influence of Pretreatment and Reaction Conditions, J. Catal. 2016, 341, 160 179 .

15. Panagiotopoulou, P.; Kondarides, D. I.; Verykios, X. E., Selective Methanation of CO over Supported Ru Catalysts, Appl. Catal. B 2009, 88, 470-478.

16. Kowalczyk, Z.; Stolecki, K.; Rarog - Pilecka, W.; Miskiewicz, E.; Wiczkowska, E.; Karpinski, Z., Supported Ruthenium Catalysts for Selective Methanation of Carbon Oxides at very Low $\mathrm{CO}_{\mathrm{x}} / \mathrm{H}_{2}$ Ratios, Appl. Catal. A 2008, 342, 35-39.

17. Eckle, S.; Denkwitz, Y.; Behm, R. J., Activity, selectivity, and adsorbed reaction intermediates/reaction side products in the selective methanation of $\mathrm{CO}$ in reformate gases on supported Ru catalysts, J. Catal. 2010, 269, 255-268.

18. Eckle, S.; Anfang, H.-G.; Behm, R. J., Reaction Intermediates and Side Products in the Methanation of $\mathrm{CO}$ and $\mathrm{CO}_{2}$ over Supported Ru Catalysts, J. Phys. Chem. C 2011, 115, 1361-1367.

19. Tada, S.; Kikuchi, R.; Takagaki, A.; Sugawara, T.; Oyama, S. T.; Urasaki, K.; Satokawa, S., Study of RuNi/TiO ${ }_{2}$ Catalysts for Selective CO Methanation, Appl. Catal. B 2013, 140-141, 258-264.

20. Urasaki, K.; Tanpo, Y.; Nagashima, Y.; Kikuchi, R.; Satokawa, S., Effects of Preparation Conditions of $\mathrm{Ni} / \mathrm{TiO}_{2}$ Catalysts for Selective $\mathrm{CO}$ Methanation in the Reformate gas, Appl. Catal. A 2013, 452, 174-178.

21. Lausche, A. C.; Medford, A. J.; Khan, T. S.; Xu, Y.; Bligaard, T.; Abild-Pedersen, F.; Nørskov, J. K.; Studt, F., On the Effect of Coverage-Dependent Adsorbate-Adsorbate Interactions for CO Methanation on Transition Metal Surfaces, J. Catal. 2013, 307, 275-282.

22. Tada, S.; Kikuchi, R.; Takagaki, A.; Sugawara, T.; Oyama, S. T.; Satokawa, S., Effect of Metal Addition to $\mathrm{Ru} / \mathrm{TiO}_{2}$ Catalyst on Selective CO Methanation, Catal. Today 2014, 232, 16-21.

23. Abdel-Mageed, A. M.; Eckle, S.; Behm, R. J., Water Assisted Dispersion of Ru Nanoparticles: The Impact of Water on the Activity and Selectivity of Supported Ru 
Catalysts during the Selective Methanation of $\mathrm{CO}$ in $\mathrm{CO}_{2}$-Rich Reformate, J. Catal. 2016, 335, 79-94.

24. Krishna, K. R.; Bell, A. T., An Isotopic Tracer Study of the Deactivation of Ru/TiO 2 Catalysts during Fischer-Tropsch Synthesis, J. Catal. 1991, 130, 597-610.

25. Takakusagi, S.; Chun, W. J.; Uehara, H.; Asakura, K.; Iwasawa, Y., PolarizationDependent Total-Reflection Fluorescence X-ray Absorption Fine Structure for 3D Structural Determination and Surface Fine Tuning, Top. Catal. 2013, 56, 1477-1487.

26. Carballo, J. M. G.; Finocchio, E.; Garcia-Rodriguez, S.; Ojeda, M.; Fierro, J. L. G.; Busca, G.; Rojas, S., Insights into the Deactivation and Reactivation of $\mathrm{Ru} / \mathrm{TiO}_{2}$ during Fischer-Tropsch Synthesis, Catal. Today 2013, 214, 2-11.

27. Dalla Betta, R. A., CO Adsorption on Supported Ruthenium, J. Phys. Chem. 1975, 79, 2519-2525.

28. Dalla Betta, R. A.; Shelef, M., Heterogeneous Methanation: In-situ Infrared Spectroscopic Study of $\mathrm{Ru} / \mathrm{Al}_{2} \mathrm{O}_{3}$ During the Hydrogenation of CO, J. Catal. 1977, 48, 111-119.

29. Newville, M., IFEFFIT : Interactive XAFS Analysis and FEFF Fitting, J. Synchrotron Rad. 2001, 8, 322-324.

30. Ravel, B.; Newville, M. A. T. H., ATHENA, ARTEMIS, HEPHAESTUS: Data Analysis for X-ray Absorption Spectroscopy Using IFEFFIT, J. Synchrotron Rad. 2005, $12,537-541$.

31. Lee, W. H.; Ko, Y. K.; Byun, I. J.; Seo, B. S.; Lee, J. G., Chemical Vapor Deposition of an Electroplating $\mathrm{Cu}$ Seed Layer Using Hexafluoracetylacetonate $\mathrm{Cu}(1,5-$ dimethylcyclooctadiene), J. Vac. Sci. Technol. A 2001, 19, 2974-2978.

32. Eckle, S. Investigations of the Kinetics and Mechanism of the Selective Methanation of $\mathrm{CO}$ in $\mathrm{CO}_{2}$ and $\mathrm{H}_{2}$-Rich Reformates Over Ru Supported Catalysts. PhD Thesis, Ulm University, 2012.

33. Ankudinov, A. L.; Ravel, B.; Rehr, J. J.; Conradson, S. D., Real-Space MultipleScattering Calculation and Interpretation of x-ray-Absorption Near-Edge Structure, Phys. Rev. B 1998, 58, 7565-7576.

34. Koningsberger, D. C.; Mojet, B. L.; van Dorssen, G. E.; Ramaker, D. E., XAFS Spectroscopy; Fundamental Principles and Data Analysis, Top. Catal. 2000, 10, 143 155.

35. Kokoric, V.; Widmann, D.; Wittmann, M.; Behm, R. J.; Mizaikoff, B., Infrared Spectroscopy via Substrate-Integrated Hollow Waveguides: A Powerful Tool in Catalysis Research, Analyst 2016, 141, 5990-5995. 
36. Prairie, M. R.; Renken, A.; Highfield, J. G.; Thampi, K. R.; Grätzel, M., A Fourier Transform Infrared Spectroscopic Study of $\mathrm{CO}_{2}$ Methanation on Supported Rhodium, $J$. Catal. 1991, 129, 130-144.

37. Gupta, N. M.; Kamble, V. S.; Iyer, R. M.; Ravindranathan Thampi, K.; Grätzel, M., FTIR Studies on the $\mathrm{CO}, \mathrm{CO}_{2}$ and $\mathrm{H}_{2} \mathrm{Co}$-Adsorption over $\mathrm{Ru}-\mathrm{RuO}_{\mathrm{x}} / \mathrm{TiO}_{2}$ Catalyst, Catal. Lett. 1993, 21, 245-255.

38. Robbins, J. L., Chemistry of Supported Ru: CO-Induced Oxidation of Ru at $310 \mathrm{~K}, \mathrm{~J}$. Catal. 1989, 115, 120-131.

39. Mizushima, T.; Tohji, K.; Udagawa, Y.; Ueno, A., EXAFS Study of the CO Adsorption Induced Morphology Change in Ruthenium Clusters Supported on Alumina, J. Phys. Chem. 1990, 94, 4980-4985.

40. Gupta, N. M.; Kamble, V. S.; Kartha, V. B.; Iyer, R. M.; Thampi, K. R.; Gratzel, M., FTIR Spectroscopic Study of the Interaction of $\mathrm{CO}_{2}$ and $\mathrm{CO}_{2}+\mathrm{H}_{2}$ Over Partially Oxidized $\mathrm{Ru} / \mathrm{TiO}_{2}$ Catalyst, J. Catal. 1994, 146, 173-184.

41. Londhe, V. P.; Kamble, V. S.; Gupta, N. M., Effect of Hydrogen Reduction on the CO Adsorption and Methanation Reaction over $\mathrm{Ru} / \mathrm{TiO}_{2}$ and $\mathrm{Ru} / \mathrm{Al}_{2} \mathrm{O}_{3}$ Catalysts, J. Mol. Catal. A 1997, 121, 33-44.

42. Fisher, A.; Bell, A. T., In-Situ Infrared Study of Methanol Synthesis from $\mathrm{H}_{2} / \mathrm{CO}_{2}$ Over $\mathrm{Cu} / \mathrm{SiO}_{2}$ and $\mathrm{Cu} / \mathrm{ZrO}_{2} / \mathrm{SiO}_{2}$, J. Catal. 1997, 172, 222-237.

43. Kim, Y. K.; Maeng, J. Y.; Lee, S. Y.; Kim, S., Growth of Properties of Ultrathin Fe Over Layers Growth on Highly Stepped Cu(111) Surface, Appl. Surf. Sci. 2000, 174, 316-323.

44. Keresszegi, C.; Grunwaldt, J. D.; Mallat, T.; Baiker, A., In situ EXAFS study on the Oxidation state of $\mathrm{Pd} / \mathrm{Al}_{2} \mathrm{O}_{3}$ and $\mathrm{Bi}-\mathrm{Pd} / \mathrm{Al}_{2} \mathrm{O}_{3}$ During the Liquid-Phase Oxidation of 1Phenylethanol, J. Catal. 2004, 222, 268-280.

45. Weiher, N.; Bus, E.; Delannoy, L.; Louis, C.; Ramaker, D. E.; Miller, J. T.; van Bokhoven, J. A., Structure and Oxidation State of Gold on Different Supports Under Various CO Oxidation Conditions, J. Catal. 2006, 240, 100-107.

46. Moulder, J. F.; Stickle, W. F.; Sobol, P. E.; Bomben, K. D. Handbook of X-ray Photoelectron Spectroscopy, Perkin Elmer Corp.: Eden Prairie/USA, 1992.

47. Castillo, R.; Koch, B.; Ruiz, P.; Delmon, B., Influence of the Amount of Titania on the Texture and Structure of Titania Supported on Silica, J. Catal. 1996, 161, 524-529.

48. Kruse, N.; Chenakin, S., XPS Characterization of $\mathrm{Au} / \mathrm{TiO}_{2}$ Catalysts: Binding Energy Assessment and Irradiation Effects, Appl. Catal. A 2011, 391, 367-376.

49. Tauster, S. J.; Fung, S. C.; Garten, R. L., Strong Metal-Support Interactions: Group 8 Noble Metals Supported on $\mathrm{TiO}_{2}$, J. Am. Chem. Soc. 1978, 100, 170-175. 
50. Tauster, S. J.; Fung, S. C.; Baker, R. T. K.; Horsley, J. A., Strong Interactions in Supported-Metal Catalysts, Science 1981, 211, 1121-1125.

51. Tauster, S. J., Strong Metal-Support Interactions, Acc. Chem. Res. 1987, 20, 389-394.

52. Dulub, O.; Hebenstreit, W.; Diebold, U., Imaging Cluster Surfaces with Atomic resolution. The Strong Metal-Support Interaction State of Pt Supported on $\mathrm{TiO}_{2}$ (110), Phys. Rev. Lett. 2000, 84, 3646-3649.

53. Wang, L.; Clancy, P., Kinetic Monte Carlo Simulation of the Growth of Polycrystalline Cu Films, Surf. Sci. 2001, 473, 25-38.

54. Miao, L.; Jin, P.; Kaneko, K.; Terai, A.; Nabatova-Gabain, N.; Tanemura, S., Preparation and Characterization of Polycrystalline Anatase and Rutile $\mathrm{TiO}_{2}$ Thin Films by RF- Magnetron Sputtering, Appl. Surf. Sci. 2003, 212-213, 255-263.

55. Yang, H. G.; Sun, C. H.; Qiao, S. Z.; Zou, J.; Liu, G.; Smith, S. C.; Cheng, H. M.; Lu, G. Q., Anatase $\mathrm{TiO}_{2}$ Single Crystals with a Large Percentage of Reactive Facets, Nature 2008, 453, 638-642.

56. King, D. L., A Fischer-Tropsch study of Supported Ruthenium Catalysts, J. Catal. 1978, 51, 386-397.

57. Kellner, C. S.; Bell, A. T., Effects of Dispersion on the Activity and Selectivity of Alumina-Supported Ruthenium Catalysts for Carbon Monoxide Hydrogenation, $J$. Catal. 1982, 75, 251-261.

58. Kelley, R. D.; Goodman, D. W., Catalytic Reaction over Single Crystal Nickel and Ruthenium: Reaction Kinetics on Different Crystal Planes and the Correlation of Surface Carbide Concentration with Reaction Rate, Surf. Sci. 1982, 123, L743-L749.

59. Che, M.; Bennet, C. O., The Influence of Particle size on the Catalytic Properties of Supported Metals, Adv. Catal. 1989, 36, 55-172.

60. Masini, F.; Strebel, C. E.; McCarthy, D. N.; Nierhoff, A. U. F.; Kehres, J.; Fiordaliso, E. M.; Nielsen, J. H.; Chorkendorff, I., Methanation on Mass-Selected Ru Nanoparticles on a Planar $\mathrm{SiO}_{2}$ Model Support: The Importance of Under-Coordinated Sites, J. Catal. 2013, 308, 282-290.

61. Vendelbo, S. B.; Johansson, M.; Nielsen, J. H.; Chorkendorff, I., Is the Methanation Reaction Over Ru Single Crystals Structure Dependent?, Phys. Chem. Chem. Phys. 2011, 13, 4486-4493.

62. Evans, M. G.; Polanyi, N. P., Inertia and Driving Force of Chemical Reactions, Trans. Faraday Soc. 1938, 34, 11-29. 
3. Ouyang, R.; Liu, J.-X., Li, W. X., Atomistic Theory of Ostwald Ripening and Disintegration of Supported Metal Particles under Reaction Conditions. J. Am. Chem. Soc. 2013, 135, 1760-1771.

64. Munnik, P.; Velthoen M.E.Z.; de Jongh, P. E.; de Jong, K. P.; Gommes, C. J., Nanoparticle Growth in Supported Nickel Catalysts during Methanation Reaction Larger is Better, Angew. Chem. Int. Ed. 2014, 53, 9493-9497.

65. Prieto, G.; Zecevic, J.; Friedrich, H.; de Jong, K. P.; de Jongh, P. E., Towards Stable Catalysts by Controlling Collective Properties of Supported Metal Nanoparticles, Nature Mater. 2013, 12, 34-39.

66. Migani, A.; Vayssilov, G. N.; Bromley, S. T.; Illas, F.; Neyman, K. M., Dramatic Reduction of the Oxygen Vacancy Formation Energy in Ceria Particles: A Possible Key to their Remarkable Reactivity at the Nanoscale, J. Mater. Chem. 2010, 20, 1053510546.

67. Djinovic, P.; Galletti, C.; Specchia, S.; Specchia, V., Ru-based Catalysts for CO Selective Methanation Reaction in $\mathrm{H}_{2}$-rich Gases, Catal. Today 2011, 164, 282-287.

68. Miyao, T.; Shen, W.; Chen, A.; Higashiyama, K.; Watanabe, M., Mechanistic Study of the Effect of Chlorine on Selective CO Methanation over Ni Alumina-based Catalysts, Appl. Catal. A 2014, 468, 187-192. 


\section{Table of Contents}

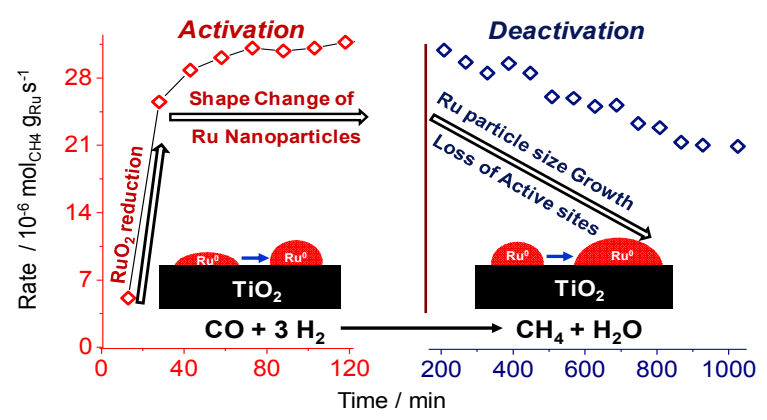

